BULLETIN Bulletin hispanique

HispaniQuE Université Michel de Montaigne Bordeaux

114-1 | 2012

Varia

\title{
La vocación helenística de Julio Cortázar
}

Sus lecturas y su formación clásica en el Mariano Acosta (1929-1936)

\section{Aagje Monballieu}

\section{(2) OpenEdition}

Journals

Edición electrónica

URL: http://journals.openedition.org/bulletinhispanique/1913

DOI: 10.4000/bulletinhispanique.1913

ISSN: 1775-3821

Editor

Presses universitaires de Bordeaux

\section{Edición impresa}

Fecha de publicación: 1 junio 2012

Paginación: 383-410

ISBN: 978-2-86781-812-7

ISSN: 0007-4640

\section{Referencia electrónica}

Aagje Monballieu, «La vocación helenística de Julio Cortázar », Bulletin hispanique [En línea],

114-1 | 2012, Publicado el 01 junio 2015, consultado el 19 abril 2019. URL : http://

journals.openedition.org/bulletinhispanique/1913; DOI : 10.4000/bulletinhispanique.1913

Este documento fue generado automáticamente el 19 abril 2019.

Tous droits réservés 


\title{
La vocación helenística de Julio Cortázar
}

\author{
Sus lecturas y su formación clásica en el Mariano Acosta (1929-1936)
}

Aagje Monballieu

La parte mitológica de esta investigación se ha podido realizar en el marco del proyecto BOF

B/06681/01 de la Universidad de Gante; la parte filosófica gracias al proyecto FWO G.0126.08 del

profesor Danny Praet. Por lo demás, agradezco, en mero orden alfabético, a Alfredo Barrios, Izaskun

Egia, Jorge O. Milone, Siska Ott y Danny Praet sus sugerencias útiles para mejorar el presente texto.

La reproducción de las fichas de mitología griega se la debo a la amabilidad de Facundo de Almeida, dueño actual del fichero. Le doy también las gracias al profesor emérito Patrick Collard por haberme iniciado en el mundo de Cortázar.

«Yo sabía y sé una barbaridad sobre mitología», le escribió Julio Cortázar en 1967 a Graciela de Sola, al contestar una pregunta de la crítica acerca de Los reyes (1949), y agregó, entre paréntesis: «no por nada fui alumno de don Arturo Marasso» ${ }^{2}$. Es sabido este profundo interés del escritor y se refleja de manera constante en su obra. Como se puede observar, no sólo el poema dramático sobre el Minotauro, sino también varios cuentos («Circe», «Las ménades» $\mathrm{y}$ «Casa tomada», por sólo mencionar algunos), novelas (pienso en Los premios y Rayuela), y hasta el ensayo literario Imagen de John Keats, dejan constancia de la fascinación cortazariana con los mitos griegos. Su afición por el mundo clásico no se limita al campo de la mitología, sino que se manifiesta, además, en sus amplios conocimientos de la filosofía, la literatura y el arte de la antigüedad, que igualmente han tenido eco en sus textos literarios ${ }^{3}$.

2 A pesar de la omnipresencia de la tradición clásica en la obra de Cortázar, hasta ahora la crítica no ha ahondado en las raíces de esta afición: la formación clásica del joven Julio Florencio en la Escuela Normal «Mariano Acosta» (1929-1936) y las lecturas complementarias -anotadas y fechadas ${ }^{4}-$ de la literatura griega y romana que el alumno realizó entonces por su propia cuenta. Me cuesta creer que hasta ahora esta última pista todavía no haya sido explorada ${ }^{5}$, sobre todo porque desde 1993 la biblioteca personal de Cortázar, tal como se encontraba en su última casa parisiense, se ha abierto al público en la Fundación Juan March de Madrid. Aunque se trata naturalmente de una selección de las 
obras griegas y latinas que había leído ${ }^{6}$, es mi intención reconstruir en estos párrafos, dentro de lo posible, la trayectoria que ha seguido Cortázar como lector de los autores clásicos ubicando estas lecturas en el contexto didáctico del Mariano Acosta.

\section{La Escuela Normal «Mariano Acosta»}

3 Después de haber terminado sus estudios primarios en la Escuela Elemental número 10 de Banfield ${ }^{7}$, Julio Florencio ingresa en marzo de 1929 en la Escuela Normal «Mariano Acosta» en Buenos Aires, instituto cuyo proyecto pedagógico nacionalista no le agradó en absoluto. En esta escuela había, durante los gobiernos de Uriburu (1930-1932) y de Justo (1932-1938), «una tentativa sistemática o no [...] de ir deformando las mentalidades de los alumnos para encaminarlos a un terreno de conservadurismo, de nacionalismo, de defensa de los valores patrios; en una palabra, fabricación de pequeños fascistas» ${ }^{8}$. En breve, para Cortázar, la Escuela Normal, esa «jaula de papagayos de la calle Urquiza» ${ }^{9}$, fue «una tremenda estafa que [1]e hizo mucho daño» ${ }^{10}$.

4 Sin embargo, en el Mariano Acosta también tenía muchos amigos con quienes se reunía en «La guarida»" para hablar de literatura, pintura, música, filosofía, política, etc. Este «club» formaba «una especie de célula de defensa contra la mediocridad de casi todos los profesores y los compañeros $»^{12}$. Entre los miembros no sólo se encontraban varios condiscípulos de Julio Florencio, tales como «Paco» Reta, Eduardo Jonquières y Jorge D’Urbano, sino también algunos profesores de la Escuela Normal, entre los cuales los únicos dos profesores -«iDos sobre cien!»»3- a quienes Cortázar recuerda con ternura. Se trata del mencionado Arturo Marasso y de Vicente Fatone, que desempeñaron un papel decisivo en la formación clásica del joven Cortázar y con quienes el alumno mantenía una buena relación. Fueron de «esa clase de profesores con los que un buen día podés ir a su casa y se crea una relación que duró muchos años»" Asimismo, «[l]e abrieron perspectivas, [1]e criticaron, [1]e mostraron [sus] equivocaciones, [sus] errores de muchacho, y [1]e metieron por un camino de estudio más severo y más hermoso al mismo tiempo» ${ }^{15}$, además de que le permitieron darse cuenta de su vocación literaria.

\section{Las clases de literatura griega y latina de Arturo Marasso (1933-1934)}

5 Para la formación clásica del joven Cortázar fue crucial la influencia de Arturo Marasso (1890-1970), gran humanista que era helenista, poeta y cervantista a la vez ${ }^{16}$. Su curso de literatura latina y griega, denominado sorprendentemente «Literatura Oriental, Griega y Latina», que Cortázar siguió durante el primer año del profesorado, esto es, entre 1933 y 1934, lo situó plenamente en el mundo de la mitología clásica. La profunda impresión que dejaron en Cortázar las clases de literatura griega y latina también se desprende de una carta posterior, en la que recuerda las palabras de su maestro: «Mas el destino -la Moira, como diría don Arturo- lo ha querido así» (C I: 40). Además de ser su maestro, Marasso también le facilitó el acceso a los libros clásicos que Cortázar en ese momento no podía comprar, dada la pobreza de su familia. «En ese tiempo yo no tenía ni un centavo», recuerda, «entonces él me hacía ir a su casa y me prestaba sus libros»» ${ }^{17}$. La importancia que tuvo Marasso en su formación clásica también se manifiesta más de diez años después, cuando Cortázar, que ya había pasado por Mendoza, le dedicó su ensayo «La 
urna griega en la poesía de John Keats» (1946), que más tarde formará parte de Imagen de John Keats (1951) ${ }^{18}$. En los últimos años de su vida, Cortázar calificaría la visión que tenía entonces de la cultura clásica como «la imaginación adolescente idealizada a través de Leconte de Lisle ${ }^{19}$, Winckelmann y [su] maestro Marasso $»^{20}$, visión idealizada que también se reflejaba en los poemas, no conservados, que componía en esta época. «Ahora que lo pienso», admitía, «cuando tenía veinte años [es decir, en 1934] la evocación de un emperador romano me hubiera exigido un soneto-medallón o una elegía-estela: poesía de lujo como se practicaba en la Argentina de ese tiempo» (OC IV: 139).

6 No es de extrañar el interés del joven Cortázar por la antigüedad clásica. Su afición por los mitos griegos remonta a sus lecturas infantiles de los diez o doce años (1924-1926); recuerda Cortázar que «el ciclo del Minotauro, por ejemplo, [1]e impresionó desde muy

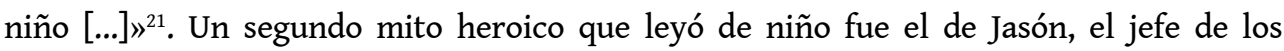
Argonautas $^{22}$. Además, no sólo le interesaban a Julio Florencio los héroes de la mitología clásica sino que también admiraba a los héroes históricos, es decir, a los guerreros, los césares romanos y a Julio César, en particular ${ }^{23}$. Otra faceta de la antigüedad que había descubierto durante su infancia fue la poesía tal como la conocía del Tesoro de la Juventud, su "gran lectura de niño»" ${ }^{24}$ "dividido en secciones, y entre ella El libro de la poesía que abarcaba un enorme espectro desde la Antigüedad hasta el Modernismo» (OC IV: 119). La impronta profunda que la cultura clásica había dejado en Julio Florencio ya se reflejaba muy temprano en sus versos infantiles, a saber, en el poema "Apóstrofe», que escribió para su hermana Ofelia, cuando él tenía aproximadamente catorce años ${ }^{25}$. En este poema le toma el pelo a «Memé» y compara las ondas que ella tenía en el cabello con figuras monstruosas de la mitología clásica, tales como las furias, las parcas y las diosas del Averno (OC IV: 577) ${ }^{26}$.

7 En cuanto a las lecturas que hizo con su maestro Marasso, Cortázar menciona a varios autores griegos pero solo a un filósofo, Platón, cuyos diálogos completos leyó con él ${ }^{27}$. Ya de muchacho Cortázar tenía un profundo interés por la filosofía y muy temprano, a los 16 o 17 años $^{28}$, se había dejado impresionar por la lectura, en francés ${ }^{29}$, de los Diálogos platónicos: «[...] I don't know what I understood of them, but I was deeply moved by Plato's

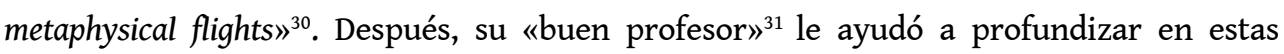
lecturas que había hecho por su propia cuenta: «[De muchacho] empecé a leer a Platón y Aristóteles, tuve un buen profesor en la escuela que me ayudó en ese plano y me entusiasmé con temas como la teoría del conocimiento y la metafísica» ${ }^{32}$. Su gran fascinación por la filosofía platónica también se manifestó en un ensayo extenso que dedicó al Parménides de Platón, y que, según un comentario irónico posterior,

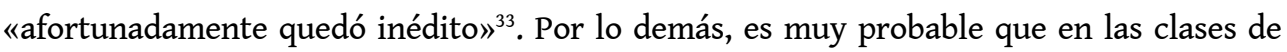
Marasso también se incluyeran a los filósofos presocráticos, puesto que a Cortázar «[l]e interesaron los presocráticos y luego Platón» ${ }^{34}$, porque la obra platónica ya de por sí contiene muchas referencias a la filosofía arcaica y porque en un apunte personal de 1939 Cortázar ya se refiere a la filosofía de Heráclito ${ }^{35}$, uno de los presocráticos más destacados.

8 Respecto a los demás autores clásicos leídos con Marasso, Cortázar menciona los nombres de Homero, Teócrito, Píndaro ${ }^{36}$ y Esquilo ${ }^{37}$. Al evocar estas lecturas de su adolescencia ${ }^{38}$, recuerda «las lágrimas que [1]e había arrancado la muerte de Patroclo en la Ilíada, la fascinación de Esquilo y Hesíodo, la complacencia nada equívoca de los diálogos pastoriles de Teócrito, y detrás la sombra mayor y un poco más retórica de Píndaro [...]» (OC IV: 205). Esta lista de autores leídos se completa con el nombre de Sófocles que Marasso le 
hizo leer también ${ }^{39}$. En esta época probablemente también se familiarizó con las tragedias de Eurípides ${ }^{40}$ y la obra de otros poetas griegos, tales como Baquílides de Ceos, Safo y Corina $^{41}$. Sorprendentemente, aunque Marasso también fue su profesor de latín, que «[1]e metió en el mundo griego y latino»» ${ }^{42}$, Cortázar no menciona la lectura conjunta de ningún autor romano.

Bajo el impulso de su maestro, el buen alumno Florencio Cortázar ${ }^{43}$ hasta tuvo «una fugaz vocación de helenista» (OC IV: 332) que se manifestó en la redacción de un ensayo sobre Píndaro que, aunque Marasso lo consideró digno de publicación, finalmente quedó inédito ${ }^{44}$. La culpa la tenía el director de la escuela normal, «matemático y cazador de patos» (OC IV: 205), que "puso una cara cadavérica y le hizo saber [a Marasso] que los créditos no se destinaban a esas pavadas» (OC IV: 205), a gran decepción del maestro y del alumno: « Exeunt Píndaro y gran tristeza de don Arturo Marasso y del autor del ensayo...» (OC IV: $205)^{45}$

10 La mayoría de los autores griegos a los que Cortázar había leído en las clases de Marasso están representados en su biblioteca personal. Hoy en día, en la Biblioteca Cortázar todavía se pueden consultar las obras de Homero, Hesíodo y Teócrito, compradas en el '33, que también contienen los Himnos órficos, las Odas anacreónticas y la obra de Bión, Mosco y Tirteo. De los nombres citados sólo falta en su biblioteca una edición de Píndaro y de Esquilo, que debe haber poseído también en aquel momento. Su ejemplar personal de Sófocles sólo data de 1968, pero ya en 1933 disponía de una edición barata, la misma de Teócrito y Esquilo, puesto que menciona ${ }^{46}$ una visita a la librería Ateneo, en la que «había comprado Esquilo, Sófocles, Teócrito, en los tomitos a un peso de Prometeo, editados en Valencia, ¿no los dirigía Blasco Ibañez?» (OC II: 439)

11 Veamos ahora qué nos enseñan estas obras griegas sobre los conocimientos clásicos que tenía Julio Florencio y sobre la manera en la que leyó a los autores helénicos, siguiendo el orden cronológico de la compra y empezando por las epopeyas homéricas.

\section{Lectura de la Ilíada de Homero (marzo de 1933)}

12 Como se mencionó anteriormente, la edición de la Ilíada de Homero (s. VIII a. C.) que el joven Cortázar compró a los dieciocho años con sus primeros pesos pertenece a la serie barata de los «tomitos a un peso» (OC II: 439) de la editorial Prometeo (Valencia) ${ }^{47}$. El libro, en dos tomos, es una traducción en segundo grado, que consistía en una versión española que Germán Gómez de la Mata había basado en la traducción francesa de Leconte de Lisle ${ }^{48}$, «a pesar de todas las modificaciones que eso significaba» ${ }^{49}$.

13 Sin embargo, su primera lectura de la Ilíada fue un choque tremendo ${ }^{50}$. Cortázar recuerda que al avanzar en la lectura, «sobre todo hacia la última etapa del desenlace, la lenta aproximación al combate final de Héctor y Aquiles $»^{51}$, entró en un estado alucinatorio, «este estado prácticamente anormal en que uno deja de vivir en sus condiciones habituales para pasar a un estado en el que todo es posible y por donde entran las cosas más inesperadas, más extrañas y a veces más maravillosas» ${ }^{52}$. Este estado lo describe también como un «estado de pasaje» en que él se colocó del otro lado del puente y vio las cosas de otra manera ${ }^{53}$. Recuerda también que estaba tan absorto en la lectura de la Ilíada que los miembros de su familia se preocupaban porque él «daba vueltas como un zombi por la casa y lo único que [l]e interesaba era volver a [su] habitación para terminar la lectura $\aleph^{54}$. 
$14 \mathrm{Al}$ volver a su ejemplar de la Ilíada, el primer tomo, que incluye los primeros doce cantos, observamos que contiene más anotaciones de su mano que el segundo. Antes de comentar estos apuntes, nos dedicamos brevemente a los pasajes subrayados por Cortázar que quedan sin anotaciones. De las frases subrayadas en el primer canto nos interesa sobre todo la risa «homérica» de los dioses, expresión que el propio Cortázar utilizará en una carta del '41 (C I: 116). Los dos pasajes subrayados de la segunda rapsodia, a continuación, constan de una comparación homérica que precede el catálogo de las naves y un fragmento del propio catálogo. Más tarde, en «Uno de tantos días de Saignon» (Último round, 1969) y en Libro de Manuel (1973), Cortázar incluiría citas o «plagios» (OC III: 1213) de la Ilíada que se corresponden precisamente con estos párrafos subrayados del catálogo. Por lo demás, el único fragmento subrayado del primer tomo que tiene mayor interés para nosotros es la descripción de la flecha de Pándaro, que volverá unos años después en el soneto «Flecha» (Presencia, 1938; OC IV: 57).

Las abundantes notas al pie que redacta Julio Florencio en el primer tomo de la Ilíada son de toda índole. Las podemos dividir en cuatro categorías: se trata de información suplementaria que agrega sobre los dioses y los héroes, traducciones alternativas de ciertas palabras, comentarios del profesor Marasso y su propia apreciación literaria de determinados pasajes homéricos.

Primero, en la mayoría de sus apuntes Cortázar corrige el nombre de los personajes en su edición ${ }^{55}$, añade en una nota al pie el nombre alternativo -en griego o latín- de algunas figuras o agrega información suplementaria sobre ciertos personajes. Este tipo de información se parece a lo que el joven helenista apuntó en las fichas de su fichero de mitología griega ${ }^{56}$. Entre las notas más breves encontramos, por ejemplo, «Aquiles» en vez de «Akileo» (I, 7) $)^{57}$, «Parcas» en vez de «Keres» $(\mathrm{I}, 10)$, «Ulises» en vez de «Odiseo» (I, 11) y «Neptuno (lat)» en vez de «Poseidaón» (I, 19). En cuanto a las «fichas» más largas, nos limitamos a citar una selección:

- La «ficha» de Clitemnestra: «Seducida por Egisto, dan muerte a Agamenón luego de concluida la guerra» $(\mathrm{I}, 11)$.

- La «ficha» de Eos: «La Aurora, hermana de Helios y de Selene» (I, 22).

- La «ficha» del Euro y el Noto: «Dioses del viento. Hijos de Astreo (el cielo estrellado) y Eos (aurora); Euros (Oriente) y Notos (Sur)» (II, 32).

- La «ficha» de Iris: «símbolo de la velocidad, primitiva mensajera de los dioses (sustituida por Hermes, quedando solo al servicio de Hera)» (II, 50).

- La «ficha» de «Keirón»: «Quirón (centauro). Educó a Aquiles, a Jasón y a Asclepio» (XI, 226)

17 En segundo lugar, Cortázar se interesa por la traducción correcta del texto griego, puesto que ha realizado un análisis comparativo de su mala traducción de segundo grado, el texto griego original, probablemente en una edición escolar ${ }^{58}$, y la versión más prestigiosa de Segalá y Estalella. Cuando Gómez de la Mata traduce por ejemplo el epíteto de Alejandro (Paris) por «divino», Cortázar apunta: «Deiforme (semejante a un Dios) traduce Segalá» (III, 55). Su comentario agregado a la escena de despedida de Héctor y Andrómaca nos indica que, tras haber comparado las distintas versiones con el texto original, consideraba la versión de Segalá y Estalella superior a la de su edición barata: «Traduce con mayor perfección Segalá sonrióse a través de su rostro bañado en lágrimas» (VI, 126).

18 El contexto didáctico en el que Cortázar compró su Ilíada se desprende de una anotación suya en la que aparece el nombre de su profesor de literatura griega. Añade el nombre de 
Marasso a una explicación sobre los pigmeos que aparecen en una comparación homérica: «Africanos (Marasso)» (III, 54).

Como última categoría de notas, y quizá la más interesante, podemos considerar los comentarios cortazarianos en los que da su apreciación personal de la calidad literaria de ciertos pasajes de la Ilíada. Uno de los discursos que dirige Agamenón a sus tropas ${ }^{59}$ le provoca a Cortázar el comentario admirativo siguiente: «Notar el realismo maravilloso de este discurso de Agamenón, sublimado por el «iAh!» y las últimas palabras de advertencia» (II, 39).

Un segundo ejemplo de la admiración cortazariana por Homero lo encontramos en la escena de la despedida de Héctor y Andrómaca, que Cortázar marca con una acolada, agregando: «Qué belleza tan delicada y pura!» (VI, 129) Esta famosa escena de despedida volverá a aparecer dos veces en su propia obra literaria posterior, por ejemplo en el capítulo 20 de Rayuela (1963) en el cual se describe a la Maga como «sonriendo homéricamente entre sus lágrimas» (OC III: 134), y en Libro de Manuel, cuando Andrés le dice a Francine: «Ya, así está mejor, sonreís entre lágrimas como Andrómaca, solamente que yo no tengo nada de Héctor, carajo» (OC III: 1132).

21 Otra escena de la Ilíada que, según sus apuntes, le gustó mucho al joven Cortázar es la descripción nocturna de la tienda de Aquiles donde duermen él y su amigo Patroclo cada uno con su amante. Julio Florencio indica todo el párrafo, subraya algunas frases y deja constancia de su admiración por Homero: «iQue naturalidad admirable hay en esta descripción exenta de jaleo pudor!» (IX, 182) ${ }^{60}$

En el segundo tomo de la Ilíada, Cortázar sólo agrega una nota al pie de página y se limita a subrayar algunos pasajes en el propio texto, de los cuales me interesan sobre todo la descripción del inmenso duelo de Aquiles por la muerte de Patroclo (canto XVIII) y la écfrasis del nuevo escudo del héroe (canto XVIII).

En cuanto al dolor de Aquiles, primero, Cortázar subrayó dos pasajes en los cuales se sugiere que Aquiles quiere matarse por la muerte de su amigo, estos son: la escena en la que lo asiste su amigo Antiloco, «temeroso de que se degollase con el bronce» (XVIII, 115), y el diálogo entre Aquiles y Tetis en el cual el héroe le cuenta a su madre que prefiere morir ya (XVIII, 117). Los párrafos indicados coinciden con un testimonio posterior de Cortázar $^{61}$, en el que evoca el dolor que él había sentido al leer que Héctor había matado a Patroclo, el amigo íntimo de Aquiles; menciona «las lágrimas que [1]e había arrancado la muerte de Patroclo en la Ilíada [...]» (OC IV: 205). En una de sus primeras cartas, escrita un par de años después de esta lectura, Cortázar se refiere al deseo de venganza de Aquiles, al compararse con el héroe griego: «Y ahora, entro decididamente en el terreno polémico, dispuesto a no cortarme el cabello hasta vengar a Patroclo» (C I: 33).

De la descripción del nuevo escudo de Aquiles, en segundo lugar, Cortázar había subrayado el inicio (XVIII, 128) y el final (XVIII, 132). Aunque estos versos no van acompañados de un comentario elogioso suyo, sabía apreciar ${ }^{62}$ la manera en la que la écfrasis homérica de esta obra de arte incluía elementos estéticos ajenos al arte plástico, ya que consideraba el escudo de Homero como un «ejempl[o] admirativ[o] de interfusión deliberada» (OC IV: 1025) ${ }^{63}$.

Podemos concluir este apartado dedicado a la Ilíada con algunos testimonios personales que confirman la profunda impresión que había dejado la obra homérica en el joven Cortázar. Esta fascinación con Homero se traduce, en primer lugar, en un comentario elogioso sobre el carácter universal y la genialidad de su obra. En una carta de 1939, 
Cortázar ejemplifica sus ideas sobre las obras literarias imperecederas precisamente con la epopeya homérica: «[...] no creo que haya contradicción en el hecho de que una obra que narra hechos circunstanciales, como por ejemplo La Ilíada, siga apasionando a todo espíritu sensible a la belleza; porque el sello del genio está precisamente en dar universalidad a lo particular; en convertir una circunstancia en un arquetipo» (C I: 50).

Además, la apreciación por la obra homérica no le impide hacer referencias ligeras a personajes o aspectos típicos de la epopeya. Así, Cortázar se refiere al ceño fruncido de Zeus, tal como está presente, por ejemplo, en el primer canto de la Ilíada ${ }^{64}$, cuando le escribe a su amigo Eduardo Castagnino, en tono burlón: «Naturalmente que, frunciendo olímpicamente las cejas, estarás sumamente enojado conmigo [...]» (C I: 29). En otra carta a Castagnino, hasta imita el patronímico de la epopeya, al usar un lenguaje altisonante en este pasaje humorístico de su carta: «-jOh, Eduardo Castagnida -lo siento, pero era necesario helenizar tu apellido dada la índole de mi estilo-, no me hundas bajo el peso de tu tronitonante furor, y escucha a tu esclavo!» (C I: 39) Las cartas citadas forman la primera señal de una actitud lúdica frente a la tradición clásica.

\section{Lectura de la Odisea de Homero (1933)}

El ejemplar de la Odisea que se encuentra en la Biblioteca Cortázar, que él había adquirido en el mismo año '33, se parece mucho a la Ilíada. Se trata otra vez de la edición barata en dos tomos de la editorial Prometeo que consiste igualmente en una traducción española basada en la versión francesa de Leconte de Lisle. Además, el segundo tomo de su Odisea, que empieza con el canto XVI, contiene tres obras más que inicialmente se atribuyeron a Homero, pero que probablemente fueron escritos por otras personas: los Himnos homéricos , una serie de epigramas y la Batracomiomaquía, una parodia de la epopeya que describe la batalla entre las ranas y los ratones.

A diferencia de su ejemplar de la Ilíada, la Odisea de Cortázar casi no contiene apuntes. Las escasas notas manuscritas que hemos encontrado se sitúan en el primer tomo y en los Himnos homéricos ${ }^{65}$. En cuanto a la Odisea, en la anotación más interesante ${ }^{66} \mathrm{Julio}$ Florencio corrige un error en el texto español ${ }^{67}$ y pone la traducción correcta, seguida por la autografía del joven helenista: «del Atreida Menelao. J Florencio Cortázar» (IV, 49). El único párrafo que subrayó durante su primera lectura se encuentra en el décimo canto, cuando se describe cómo Circe transforma a los hombres de Ulises en $\operatorname{cerdos}^{68}$, un fragmento esencial para el lector de «Circe» ${ }^{69}$, el cuento de Bestiario (1951) que Cortázar dedicó a la maga homérica ${ }^{70}$.

Durante su lectura de los Himnos homéricos, corrigió un error en el texto ${ }^{71} \mathrm{y}$, más importante, dejó constancia de su apreciación personal, seguida por su firma, del verso siguiente del primer Himno a Apolo: «[...] y sus cantos serán los mejores en el porvenir.» Es ésta la exclamación solemne que el joven Cortázar apuntó en una nota al pie: «iQué suprema confianza en la inmortalidad! El verdadero talento es el que reconoce su mérito, sin falsa modestia. J. Florencio Cortázar» (151).

\section{Lectura de la obra de Hesíodo (mayo 1933)}

La edición de Hesíodo (s. VIII a. C.) que Julio Florencio compró en mayo de 1933, pertenece a la misma serie barata que su Ilíada y Odisea. Otra vez es la versión española de la traducción francesa de Leconte de Lisle editada en Prometeo. El libro contiene dos obras de 
Hesíodo -la Teogonía y Los trabajos y los días-, una obra pseudo-hesiódica (El escudo de Heracles), además de los Idilios de Bión (s. II a. C.) y de Mosco (s. II a. C.), dos poetas bucólicos tardíos, y los Himnos órficos.

La Teogonía de Cortázar, que abunda en apuntes muy diversos ${ }^{72}$, demuestra, en primer lugar, que él sabía escribir en griego, puesto que agregó los nombres Mópov y Kñpo, tal como estaban en el texto original, en un pasaje sobre Moro y la Ker (15). Cortázar también se interesaba por la manera de traducir el texto original, puesto que había comparado su versión con el texto de Hesíodo. En una nota sobre Giges apunta: «En el texto griego dice Gies o Gias» (13). Asimismo había cotejado su mala versión con la traducción prestigiosa de Segalá y Estalella, de la que cita varias veces ${ }^{73}$, y con la traducción francesa de la edición de Belles Lettres ${ }^{74}$. Como un verdadero helenista, el joven Cortázar se interesaba, además, por la crítica del propio texto griego, porque indica que un pasaje del inicio del poema es una interpolación (15).

Al igual que las obras homéricas, la Teogonía es otra de las obras que leyó con su profesor de literatura griega, a quien menciona en el apunte siguiente sobre una larga enumeración de diosas griegas: «Dice el prof. Marasso, que la etimología de cada [abreviada] diosa representa una virtud» (17). En la misma nota sigue un comentario que probablemente también sabía por Marasso y que guarda parecido con la información que recopilaba en su fichero mitológico ${ }^{75}$ : «Galatea, diosa blanca, amada por Polifemo (Teócrito, Luciano, Virgilio, Ovidio, Eurípides, Garcilaso, Luis Carillo y Sotomayor, "Stigliano" "76)» (17). Cortázar también sabía, tal vez por Marasso, cuál era la opinión de Giacomo Leopardi (1798-1837), el poeta italiano que tradujo la «Titanomaquia» de Hesíodo, sobre esta parte del poema, ya que menciona en un apunte que Leopardi la comparó «con los [pasajes] más hermosos de Homero» (34) ${ }^{77}$.

En El escudo de Heracles, segunda obra del volumen, Cortázar sólo hizo un apunte más que podemos calificar de «ficha» mitológica ${ }^{78}$. Al igual que en el caso del escudo de Aquiles, Cortázar mostraba su admiración ${ }^{79}$ por la manera en la que el poeta mezcló en su écfrasis otros elementos estéticos en este «ejempl[o] admirativ[o] de interfusión deliberada» (OC IV: 1025$)^{80}$.

Las anotaciones que hizo Julio Florencio en Los trabajos y los días son más escasas que los apuntes encontrados en la Teogonía. Aparentemente, este poema didáctico también lo había leído en las clases de literatura griega, pues apunta: «El profesor Marasso afirma que debe ser timón referida a una nave y no a un arado; la palabra griega es pedalion ${ }^{81}$ » (73). Otro punto que tiene en común con la Teogonía es el interés de Cortázar, probablemente provocado por Marasso, por la transmisión del texto griego, que se manifiesta en la anotación siguiente: «Hay dudas acerca de la autenticidad de los 10 primeros versos de esta obra. Se debe a que la invocación es hecha a las Musas de Pieria y no a las de Helicón (Musas Heliconiadas) (véase pág. 7)» (71). Al igual que en otras obras, la información que apunta en Los trabajos y los días se parece a las «fichas» mitológicas. Así, por ejemplo, comenta una diferencia mitológica entre Hesíodo y Homero, cuya obra había leído antes: «Hesíodo discrepa con Homero, ya que éste sitúa las almas de los héroes en la morada de Plutón (Hades) y Proserpina (Rapsodias X y XI de Odisea)» (78) ${ }^{82}$. El título de la obra hesiódica lo mencionará en una carta dirigida a su amiga Alejandra Pizarnik (1936-1972), en la que él comenta su entonces reciente libro de poesía, Los trabajos y las noches (1965), e invirtiendo los papeles hace referencia a la obra del poeta griego: «Un infame plagario llamado Hesíodo ha publicado un libro que se titula Los trabajos y los días» (C II: 903). 

son los Idilios de Bión, los Idilios de Mosco y los Himnos órficos. Toda la información que Cortázar apuntó en los márgenes de los Idilios de Bión, primero, corresponde a la categoría de las «fichas» de mitología ${ }^{83}$. Lo interesante es que Cortázar también manifiesta sus ganas de profundizar en sus conocimientos mitológicos, ya que había consultado el estudio de Hermann Steuding sobre la mitología griega. Concretamente, había buscado el nombre de Piritoo en este libro de consulta: «Piritoo, rey tesalio, era señor de los Lapitas (hombres de piedra) parientes de los flegios y minios - Luchó al lado de Teseo, le ayudó a robar a Helena de Esparta, y bajó con él a los Infiernos, para robar a Persefonia; ambos fueron apresados en una roca, salvándose más tarde Teseo gracias a Heracles (Steuding)» (VIII, 115).

pocos comentarios que Cortázar agrega a los Idilios de Mosco, en segundo lugar, también sirven para explicar o añadir información a los nombres mitológicos ${ }^{84}$. En la nota más larga escribe otro nombre en griego y menciona la Ilíada, que había leído

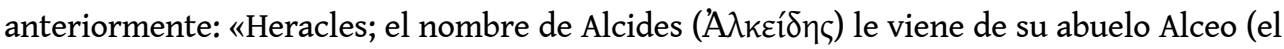
fuerte); bajó a los Infiernos donde libertó a Teseo y se apoderó de Cérbero; una leyenda más antigua (Ilíada) muestra a Heracles en Pilos (puerta del Infierno) donde hirió a saetazos a Hades y a su enemiga Hera» (III, 134).

37 En los Himnos órficos, la última obra que se ha incluido en el volumen de Hesíodo, Cortázar hace sobre todo apuntes explicativos sobre los nombres de los dioses y su etimología ${ }^{85}$. En otras de estas «fichas» da información suplementaria sobre un personaje mitológico y agrega una referencia a una obra de arte que se relaciona con la figura en cuestión. Cuando lee sobre los Curetes, por ejemplo, agrega una referencia a su presencia en un bajorrelieve ${ }^{86}$; otros ejemplos son las referencias a los templos de Nike en Atenas ${ }^{87}$ y de Demeter en Eleusis ${ }^{88}$.

38 También en el caso de los Himnos órficos se manifiesta el deseo de Cortázar de ampliar sus conocimientos mitológicos y de recurrir, por su propia iniciativa, a obras de consulta como el estudio citado de Steuding o un diccionario enciclopédico. En el estudio de Steuding, primero, busca más información sobre Plutón. Al apuntar el resultado de su búsqueda, copia el epíteto del dios en letras griegas: «Dice Steuding: "lleva como característica el cuerno de la abundancia y es festejado bajo el nombre de Plutón

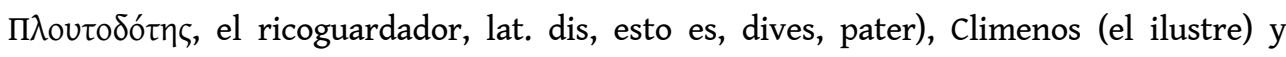
Eubuleus (el benévolo)"» (157). Una segunda fuente de información sobre la mitología que Cortázar consulta durante su lectura de los Himnos órficos es el DEHA, el Diccionario Enciclopédico Hispano-americano de Literatura, Ciencias y Artes, del que cita un fragmento sobre los Curetes: «Dice el DEHA: "se les ha confundido con los Coribantes pero según Pausanias eran de raza diferente. Rea confió a los Curetes su hijo Zeus para que Cronos no le devorara. Según mitólogos modernos, el nombre de Curetes, en sentido de sacerdotes míticos, debe darse a los ministros de Zeus cretense"» (173).

Además, observemos que también en este contexto ${ }^{89}$, Cortázar hace referencia a Arturo Marasso. Esta vez no se trata de una observación que hizo el maestro durante las clases, sino que Julio Florencio remite a la monografía que su maestro había escrito sobre la poesía de Rubén Darío: «Ver Rubén Darío, de Marasso, aún «lisis»» de Helios, pág. 180» (LXXV, 201). 


\section{Lectura de los Idilios y los Epigramas de Teócrito, la obra de Tirteo y las Odas Anacreónticas (mayo de 1933)} poeta» (71).

El último libro que encontramos en la biblioteca fechado en 1933, fue el de Teócrito, que, al igual que los otros, consiste de una versión española de la traducción francesa de Leconte de Lisle. La edición barata contiene dos obras de Teócrito de Siracusa (s. III a.C.), los Idilios y los Epigramas, los poemas de Tirteo de Esparta (s. VII a.C.) y las Odas anacreónticas, que constan de una imitación tardía de los versos de Anacreonte (s. VI a.C.).

Los Idilios de Teócrito abundan en notas de la mano de Cortázar que dan prueba de su lectura y estudio del texto clásico. Al igual que en todos los libros mencionados anteriormente, los márgenes de este libro también contienen muchas «fichas» mitológicas. A modo de ilustración copio una selección de apuntes de esta índole:

- La «ficha» de Dafnis: «Dafnis, pastor siciliano, hijo de Hermes y una ninfa; haciendo falta a la fidelidad que prometiera a la ninfa Cloe, ésta lo dejó ciego; la leyenda le atribuye la invención de la poesía bucólica» $(\mathrm{I}, 12)^{91}$.

- La «ficha» de Hécate: «Hécate es principalmente diosa de los encantamientos y conjuros; generalmente se la identifica con la luna (Selene) y su acción es nocturna» (II, 16).

- La «ficha» de Atalante: «Atalante solo quería por esposo a quien la venciera en la carrera; Hipomenes o Meilanion obtuvo de Afrodita 3 manzanas de oro que arrojó sucesivamente durante la carrera; Atalante se detuvo a recogerlas siendo así vencida» (III, 25).

Como en las obras anteriores, Cortázar hace una lectura estudiosa de los Idilios que se realiza en el contexto didáctico de las clases del maestro Marasso ${ }^{92} \mathrm{y}$ que él completa por su propia cuenta por medio de obras de consulta. Para profundizar en su estudio de la obra de Teócrito, el joven helenista consultó la Historia de la literatura griega de Wilhelm Nestle (1865-1959) ${ }^{93}$ y Las dos carátulas, el extenso estudio que hizo Paul de Saint-Victor (1827-1881) de la tragedia y la comedia griegas. Sabemos que de este último había leído el comentario a Pluto de Aristófanes ${ }^{94}$, y, más importante, a la luz de la obra cortazariana posterior, lo que había escrito de Saint-Victor sobre Las Bacantes de Eurípides. De hecho, en un comentario al idilio «Las Leneas o las Bacantes», tema que volverá en su cuento «Las ménades» (Final del juego, 1956), Cortázar apunta lo siguiente: «Véase el capítulo Las Bacantes (comentario sobre el drama homónimo de Eurípides) que hace Paul de SaintVictor en la parte correspondiente a Eurípides (pág. 152) de Las dos carátulas, y se notará la relación entre el culto de Baco y este idilio» (XXVI, 143).

Otro apunte sobre el Idilio XXII («Los Dióscuros») confirma los conocimientos que Cortázar tenía de las Odas de Píndaro. En esta nota, compara el poema de Teócrito sobre Cástor y Pólux con la Nemea $\mathrm{X}$ de Píndaro, donde aparecen los mismos personajes mitológicos: "Compárese este idilio con la descripción que hace Píndaro del combate entre los Dióscuros y los hijos de Afareo, en la Décima Nemea» (XXII, 122) ${ }^{95}$.

Es interesante, además, la admiración que siente como joven poeta por los versos de Teócrito y el Idilio XII («El amigo»), en particular. En este poema Teócrito formula el deseo siguiente: «Si acaeciera que después de doscientas generaciones alguien me dijese, a orillas del Akerón, de donde nadie vuelve: "iLa ternura que te unía a tu encantador amigo está en todas las bocas, y los jóvenes sobre todo la recuerdan!"» (XII, 71) En un comentario breve Cortázar da su apreciación del Idilio: «Se ha cumplido el deseo del 

subrayó nada en los versos de Tirteo, pero sí leyó con mucha atención las Odas anacreónticas. En este caso se observa el mismo interés del joven helenista por la traducción del texto griego, que había comparado su traducción de segundo grado con la versión más prestigiosa de Tomás Meabe. En la Oda XIII («Acerca de sí mismo»), por ejemplo, Cortázar comenta el adjetivo «afeminado» que acompaña a Atis de la manera siguiente: «¿Por qué afeminado? Castrado, mutilado, etc. es más propio y así lo traduce Meabe» (XIII, 189). En la Oda XLVIII («Acerca de sí mismo»), a continuación, cita la traducción de Meabe en otro apunte sobre el fragmento «iDadme la copa de las leyes sagradas [...]!»: «la ley de los festines (Trad. Meabe)» (XLVIII, 208). posteriores. En su monografía sobre Keats, se referirá a las Anacreónticas, al establecer una comparación entre un verso de la «Oda a Psique» y la «Oda a una urna griega» (OC IV: 1022) ${ }^{96}$. Más tarde, también se referirá a Anacreonte en Rayuela (OC III: 201) y posteriormente escribirá «Anacreonte» (Salvo el crepúsculo, 1984; OC IV: 246), un soneto inspirado en las Anacreónticas.

\section{La vocación de helenista y el fichero de mitología griega} mitología griega que había compuesto, «después de leer[se] todo Homero y Hesíodo, alentado por la bondad y el saber de Arturo Marasso» (OC IV: 332). Se trata de una iniciativa que forma parte de la «fugaz vocación de helenista» (OC IV: 332 ) que tenía en ese momento. Pese a que su maestro Marasso lo había estimulado, me parece que el joven helenista armó su fichero por interés personal. Según recuerda Eduardo Jonquières, gran amigo suyo, esta actitud minuciosa de organizar sus conocimientos mitológicos formaba parte del carácter de Cortázar: «Era un tipo metódico, ordenado hasta la obsesión, sobre todo cuando se trataba de sistematizar conocimientos, aun los más diversos: ya en la época del Mariano Acosta, se organizó dos ficheros: uno de mitología griega y otro de jazz» $»^{97}$. Además de estas ganas de sistematizar sus conocimientos, llama la atención la manera rápida y entusiasta en la que compuso este fichero. Su hermana afirma que lo confeccionó en muy poco tiempo: «En dos semanas Julio compuso un fichero minucioso que rastrillaba cielo y tierra de los griegos. A pesar del entusiasmo, el trabajo sobre mitología nunca salió a la luz»» ${ }^{98}$

El fichero de mitología griega todavía existe ${ }^{99}$. Se trata de un fichero estrictamente mitológico, aunque algunas fichas también contienen información acerca de ciertos lugares del mundo helénico. Consta de unas 250 fichas, hechas en cartulina de distintos colores ${ }^{100}$. La mayoría de las fichas Cortázar las escribió a máquina. Sin embargo, el fichero también contiene muchas otras fichas manuscritas. Algunas de las manuscritas las quiso poner a máquina más tarde, puesto que tienen un texto cruzado que dice «Rehacer esta ficha por otra», lo que demuestra otra vez la actitud sistemática del joven helenista. 
respecto a su contenido, las fichas son bastante sencillas. En líneas generales contienen el nombre griego y el nombre latino de los personajes mitológicos, una breve descripción de su genealogía y la referencia concreta a la obra griega -sobre todo figura el nombre de Hesíodo- donde aparecen mencionados. En la ficha de Apolo, por ejemplo, que inserto en el anexo, se añade su epíteto Febo, se mencionan su geneología y sus características principales, cada vez haciendo referencia a la Teogonía, y se cita un fragmento de Hesíodo sobre el dios: «Apolo y Artemisa... que son los más hermosos entre todos los Uránicos (Id. [Teogonía], 43).» Contrario a los apuntes cortazarianos en los libros de su biblioteca, en las fichas mitológicas no se refiere a Arturo Marasso, lo que confirma mi hipótesis de que se trata de una iniciativa del propio Cortázar.

\section{Las clases de filosofía de Vicente Fatone (1935-1936)}

El otro profesor de la Escuela Normal de quien Cortázar tiene buenos recuerdos, fue Vicente Fatone (1903-1962), gran filósofo y orientalista ${ }^{101}$ que daba clases de filosofía, de teoría del conocimiento y de lógica ${ }^{102}$, con quien Julio Florencio también tuvo un contacto muy personal. Sus clases de lógica, que Cortázar siguió entre 1935 y $1936^{103}$, le interesaron tanto que tenía la intención de seguir filosofía, pero más tarde Cortázar se dio cuenta de que no tenía mentalidad filosófica: «Me fascinaba, porque la filosofía te mete en lo fantástico, en

\section{Muestra del fichero mitológico de Cortázar}

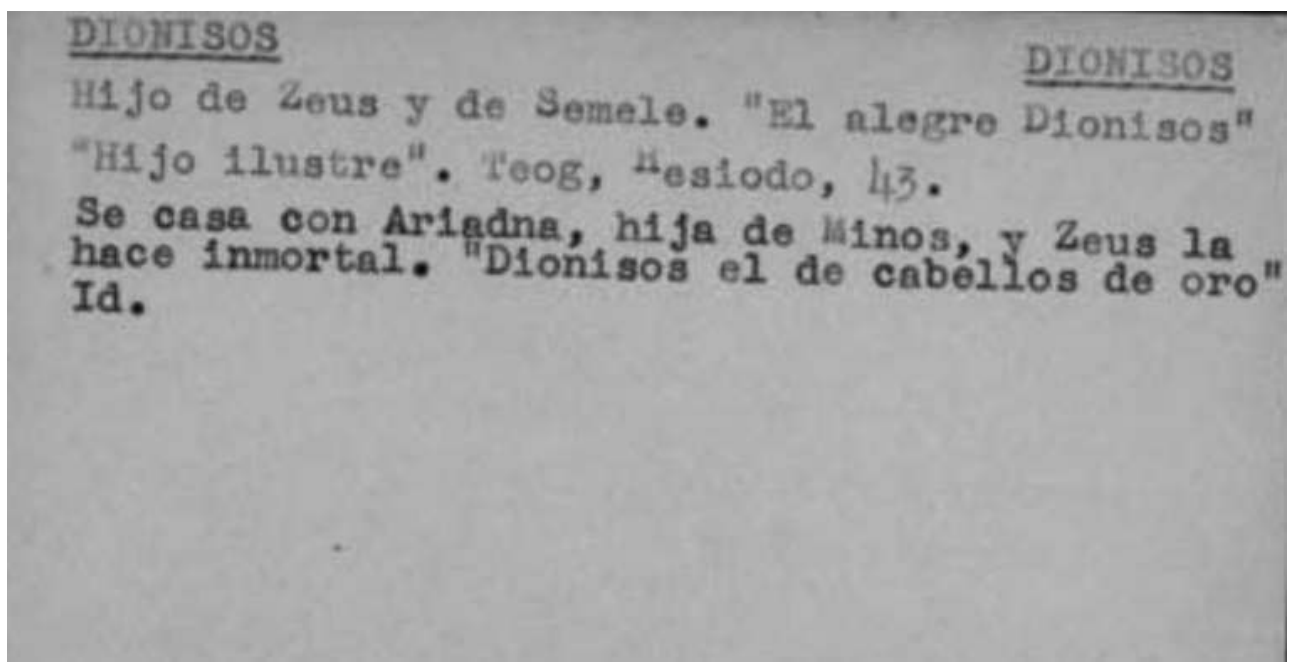



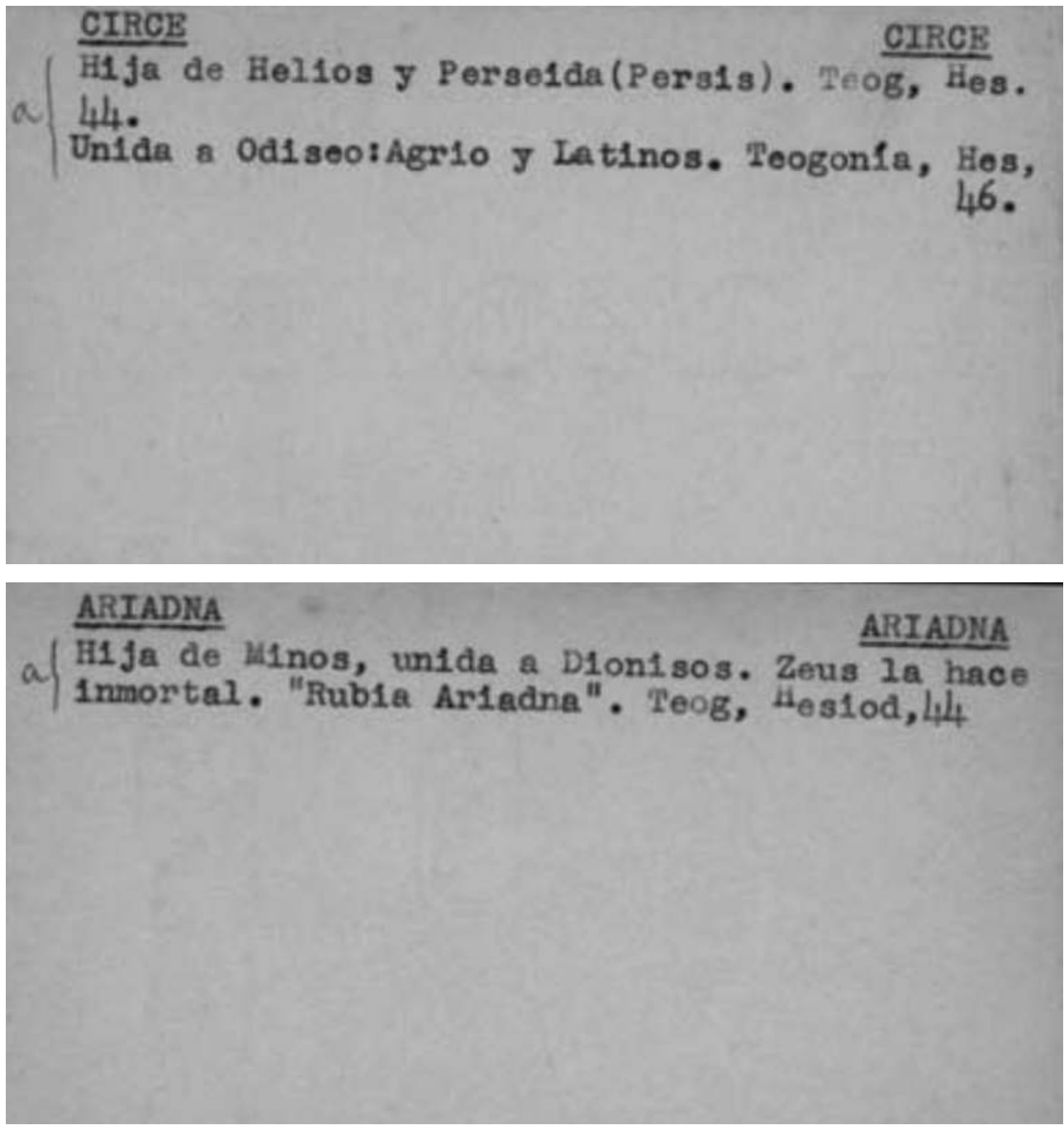

ODISEO

ODISEO

Unido a C1rce:Agrio y Lat1nos. Teog, Hes1odo, 46 "Pac1 ente Od1seo". Id. Un1do a Cal1pso:Naus1 too y itausinoo. Id, 46. 


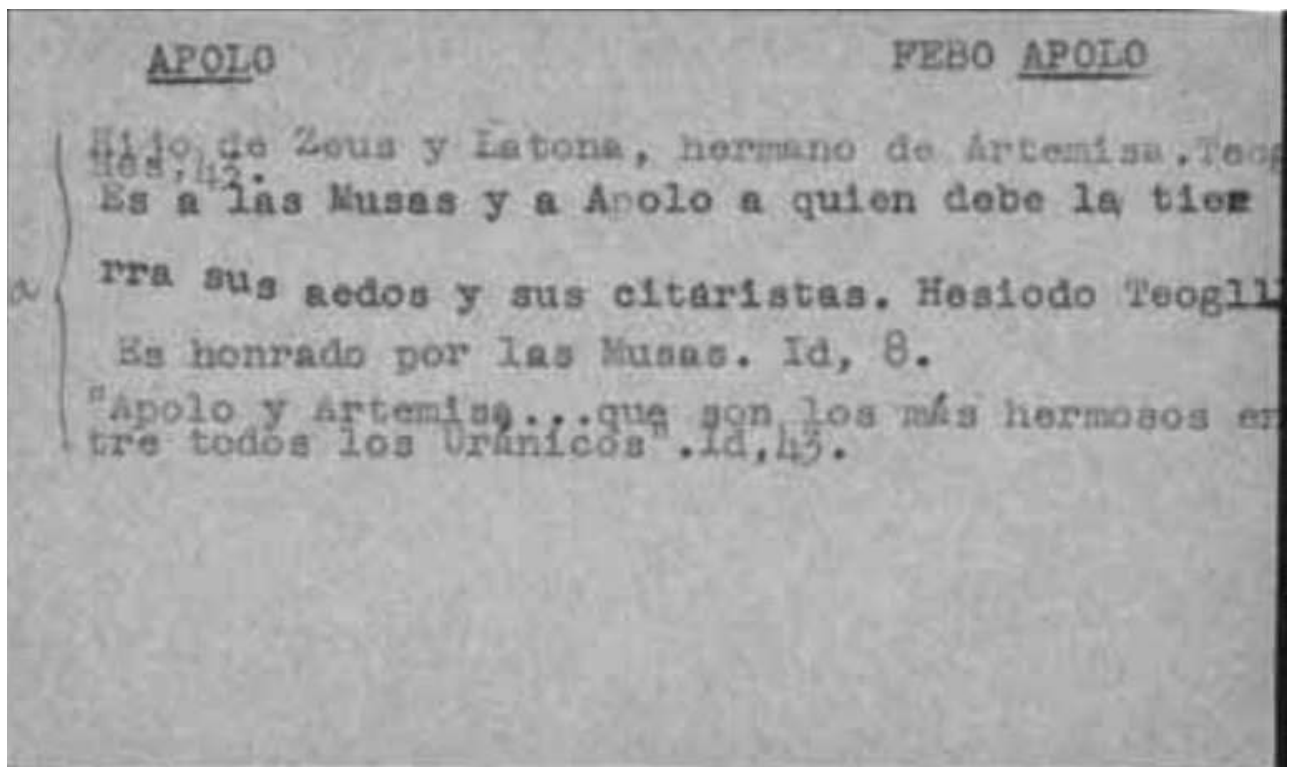

\section{ARCHIVO PERSONAL DE FACUNDO DE ALMEIDA}

lo metafísico, pero no tenía un temperamento para avanzar o sistematizar en el campo filosófico y la abandoné [...]»104. Fue con Fatone con quien Cortázar leyó la obra de Aristóteles ${ }^{105}$ y demás filósofos griegos: «Con Marasso me había leído todos los diálogos de Platón y con Fatone me metí en Aristóteles. Entonces hice toda mi formación filosófica griega y luego pasé a la Edad Media» ${ }^{106}$. Fatone le enseñó también la base de la técnica de la traducción ${ }^{107}$, que más tarde se convertirá en su profesión, «y mucho más que eso: me enseñó un rigor intelectual poco frecuente entre nosotros» (C II: 819). Su profesor también lo puso en contacto con la filosofía india y lo introdujo al pensamiento del mundo oriental ${ }^{108}$.

Ahora bien, ¿qué libros griegos compró Cortázar en la época de las clases de Fatone? En la Biblioteca Cortázar actual he podido consultar el ejemplar que él tenía de una monografía sobre el Parménides de Platón y una versión española de las comedias de Aristófanes.

\section{Lectura del Estudio sobre el «Parménides» de Platón (1936)}

53 Sólo en 1936, es decir, tres años después de los primeros libros adquiridos, Cortázar amplía su biblioteca con otro libro sobre la antigüedad clásica, libro filosófico esta vez y la única obra secundaria que se compra en su juventud: el Estudio sobre el «Parménides» de Platón de Jean Wahl (1929) ${ }^{109}$. Según indica el apunte siguiente, Cortázar debe haber leído la monografía poco después de las clases de lógica de Fatone: «[...] Lógica del juicio. Repasar mis textos de lógica.» (4) Su interés por este estudio se relaciona probablemente con la redacción de un ensayo extenso sobre el mismo diálogo platónico. La gran cantidad de párrafos subrayados ${ }^{110}$, seguidos por la nota marginal «ojo!» (p. ej. 5, 22, 27) demuestra que Cortázar había estudiado el libro muy atentamente.

El interés cortazariano por Platón forma una constante a lo largo de su vida y su obra. Tanto en sus lecturas de otros libros ${ }^{111}$, en su correspondencia personal (C II: 915), como en su obra literaria ${ }^{112}$ y ensayística ${ }^{113}$ y sus entrevistas ${ }^{114}$ Cortázar menciona la doctrina del filósofo griego. En muchas ocasiones se refiere al concepto platónico de las Ideas ${ }^{115}$, también deja constancia del carácter poético de los Diálogos ${ }^{116}$ y se refiere a algunas obras en particular, tales como el Crátilo ${ }^{117}$, el Banquete ${ }^{118}$, el Sofista y el propio Parménides ${ }^{119}$. 
En el mismo 1936, su último año en el Mariano Acosta, Cortázar compró los tomos dos y tres de las Comedias de Aristófanes (c. 456-386 a.C.), que contenían las obras siguientes: Los caballeros, La paz, Las avispas, Pluto (tomo 2); Las tesmóforas, Las aves, La asamblea de mujeres y Las ranas (tomo 3) ${ }^{125}$. Aunque ambos tomos quedan sin apuntes, una nota manuscrita en otro libro indica que Cortázar conocía bien la obra de Aristófanes ${ }^{126}$. Para terminar esta visión de conjunto quisiera mencionar también la parodia de Las ranas que Cortázar escribirá en Diario de Andrés Fava (1950), coro gracioso que hoy en día no ha perdido actualidad. Lo cito como un ejemplo que demuestra que la lectura minuciosa que hizo el joven Cortázar de las obras clásicas se combinará más tarde también con una visión a la vez lúdica y actualizada de la antigüedad. Efectivamente, en el «Coro para Las ranas 1950» es humorística la imitación que hace Cortázar del «Brekekekex coax coax», puesto que el texto sólo consta de productos comerciales populares: «-Kodak kodak kodak coca coca cola cola kodak coca kodak cola kodak coca kodak cola...» (OC II: 555).

\section{BIBLIOGRAFÍA}

Almeida Facundo, Piñeiro Liliana, Cortázar / Presencias, Buenos Aires, Fundación Internacional Argentina, 2004, 155 p.

Barrantes-Martín Beatriz, «Más allá de París: Cortázar en España, España en Cortázar», Conferencia inédita, VIII Coloquio Literario de la Feria Internacional del Libro de Monterrey «Julio Cortázar», Monterrey (México), 16-17 de octubre 2008.

Castro-Klaren Sara, «Julio Cortázar, lector. Conversación con Julio Cortázar», Cuadernos Hispanoamericanos, 1980, 364-366, 25 p.

Celorio Gonzalo, «Julio Cortázar, lector», Conferencia inédita, VIII Coloquio Literario de la Feria Internacional del Libro de Monterrey «Julio Cortázar», Monterrey (México), 16-17 de octubre 2008.

Cortázar Julio, «La urna griega en la poesía de John Keats», Obra crítica. 2, Alazraki J. (ed.), Madrid, Alfaguara, 1994, $47 \mathrm{p}$.

- Cartas. 1, 1937-1963, Bernárdez A. (ed.). Buenos Aires, Alfaguara, 2000, 647 p. [C I].

- Cartas. 2, 1964-1968, Bernárdez A. (ed.). Buenos Aires, Alfaguara, 2000, 648 p. [C II].

- Cartas. 3, 1969-1983, Bernárdez A. (ed.). Buenos Aires, Alfaguara, 2000, 524 p. [C III]. 
- Obras completas. 1, Cuentos, Yurkievich S. (ed.). Barcelona, Galaxia Gutenberg, Círculo de Lectores, 2003, 1126 p. [OC I].

- Obras completas. 2, Teatro. Novelas I, Yurkievich S. (ed.). Barcelona, Galaxia Gutenberg, Círculo de Lectores, 2004, 956 p. [OC II].

- Obras completas. 3, Novelas II, Yurkievich S. (ed.). Barcelona, Galaxia Gutenberg, Círculo de Lectores, 2004, 1341 p. [OC III].

- Obras completas. 4, Poesía y poética, Yurkievich S. (ed.). Barcelona, Galaxia Gutenberg, Círculo de Lectores, 2005, 1430 p. [OC IV].

- Obras completas. 6, Obra crítica, Yurkievich S. (ed.). Barcelona, Galaxia Gutenberg, Círculo de Lectores, 2006, 1107 p. [OC VI].

- Último round, Barcelona, Destino, 2004, 391 p.

- La vuelta al día en ochenta mundos. 2. Madrid, Siglo XXI de España editores, 2007, 198 p.

- Dunlop Carol, Los autonautas de la cosmopista. Un viaje atemporal París-Marsella, Barcelona, Muchnik, 1983, 314 p.

Deschamps Jorge R., Julio Cortázar en Banfield. Infancia y adolescencia, Buenos Aires, Orientación Gráfica, 2004, 175 p.

Fernández Cicco Emilio, El secreto de Cortázar, Buenos Aires, Belgrano, 1999, 203 p.

Fernández Naval Francisco X., Respirar por el idioma: los gallegos y Julio Cortázar, Buenos Aires, Corregidor, 2007, $211 \mathrm{p}$.

González Bermejo Ernesto, Conversaciones con Cortázar, Barcelona, Edhasa, 1978, 190 p.

Goloboff Mario, Julio Cortázar. La biografía, Buenos Aires, Seix Barral, 1998, 332 p.

Harss Luis, «Julio Cortázar, o la cachetada metafísica», Los nuestros, Buenos Aires, Sudamericana, $1975,58 \mathrm{p}$.

Hébert François, «An Interview with Julio Cortázar», en Alazraki Jaime (bajo la dirección de), Critical essays on Julio Cortázar, New York, G.K. Hall \& Co, 1999, 9 p.

Homero, Ilíada, López Eire A. (ed., trad.), Madrid, Cátedra, 2001, 1088 p.

Houvenaghel Eugenia, Monballieu Aagje, «El eterno retorno de la mujer fatal en "Circe" de Julio Cortázar», Bulletin of Hispanic Studies, 2008, 85, n 6, 13 p.

Kerr Lucille, «Interview. Julio Cortázar», Diacritics, 1974, 4, n 4, 5 p.

Marambio John Luis, Julio Cortázar y la contra-novela, Michigan, Texas Tech University, 1980, 503 p.

Mesa Gancedo Daniel, «De la casa (tomada) al café (Tortoni): historia de los dos que se entendieron: Borges y Cortázar», Variaciones Borges, 2005, 19, 23 p.

Monballieu Aagje, «Más que un amateur esclarecido. La afición de Julio Cortázar por la filosofía de Heráclito», Neophilologus, 2012, 96, $\mathrm{n}^{\circ} 2,16$ p.

Montes-Bradley Eduardo, Cortázar sin barba, Buenos Aires, Sudamericana, 2004, 393 p.

Picon Garfield Evelyn, Cortázar por Cortázar, Xalapa, Universidad Veracruzana, 1981, 135 p.

Praet Danny, Monballieu Aagje, «Reversals of Fire. The philosophy of Heraclitus as thematic subtext of Julio Cortázar's "All Fires the Fire"», Bulletin of Hispanic Studies, 2011, 88, n 8, 19 p. Prego Omar, La fascinación de las palabras. Conversaciones con Julio Cortázar, Barcelona, Muchnik, 1985, 195 p. 
Protin Sylvie, Traduire la lecture. Aux sources de Rayuela: Julio Cortázar, traducteur, Tesis doctoral inédita, Université Lumière Lyon II, 2003, 295 p.

Soriano Osvaldo, Reportaje a Julio Cortázar. En Revistero. Mágicas ruinas. [En línea]. 1983 [Página consultada el 18 de junio 2010]. Disponible en: http://magicasruinas.com.ar/revistero/esto/ revdesto155.htm

y http://magicasruinas.com.ar/revistero/esto/revdesto156.htm.

\section{ANEXOS}

\section{Obras clásicas de la Biblioteca Cortázar (1933-1936)}

\section{Obras primarias}

Aristófanes, Comedias. 2, Los caballeros. La paz. Las avispas. Pluto. Martínez Lafuente R. (trad.). Valencia, Prometeo, «Serie Libros célebres españoles y extranjeros», s.d., 244 p. [Libro firmado y fechado: «J. Florencio Cortázar, 1936».]

- Comedias. 3, Las tesmóforas. Las aves. La asamblea de las mujeres. Las ranas. Martínez Lafuente R. (trad.). Valencia, Prometeo, «Serie Libros célebres españoles y extranjeros», s.d., $258 \mathrm{p}$.

Euripides, Ten plays, Hadas M., McLean J. (trads.), New York, Bantam Books, 1960, 358 p. [Libro firmado y fechado: «Cortázar París 62».]

Hesíodo, Teogonía [Bión: Idilios. Mosco: Idilios. Himnos órficos. La Teogonía. El escudo de Heracles. Los trabajos y los días]. Traducción nueva del griego por Leconte de Lisle, Gómez de la Mata G. (trad.), Valencia, Prometeo, «Serie Libros célebres españoles y extranjeros», s.d., 205 p. [Libro firmado y fechado: «J. Florencio Cortázar, mayo 1933». En la misma página se encuentra la etiqueta de la «Librería del Colegio de Buenos Aires».]

Homero, Ilíada. Traducción nueva del griego por Leconte de Lisle. 1. Gómez de la Mata G. (trad.). Valencia, Prometeo, «Serie Libros célebres españoles y extranjeros», s.d., 241 p. [Libro firmado y fechado: «J. Florencio Cortázar, marzo 1933».]

- Ilíada. Traducción nueva del griego por Leconte de Lisle. 2. Gómez de la Mata G. (trad.). Valencia, Prometeo, «Serie Libros célebres españoles y extranjeros», s.d., 247 p. [Libro firmado y fechado: «J. Florencio Cortázar, marzo 1933».]

- Odisea. Traducción nueva del griego por Leconte de Lisle. 1. Hernández Luquero N. (trad.). Valencia, Prometeo, «Serie Libros célebres españoles y extranjeros», s.d., 245 p. [Libro firmado y fechado: «J. Florencio Cortázar, 1933».]

- Odisea. Los himnos homéricos. La Batracomiomaquía. Traducción nueva del griego por Leconte de Lisle. 2. Hernández Luquero N. (trad.). Valencia, Prometeo, «Serie Libros célebres españoles y extranjeros», s.d., 246 p. [Libro firmado y fechado: «J. Florencio Cortázar, 1933».]

Sophocles, The complete plays of Sophocles, Claverhouse Jebb R. (trad.), Hadas M. (ed.), New York, Bantam Books, 1967, 261 p. [Libro firmado y fechado: «Cortázar New Delhi 1968».] 
Teócrito, Idilios y epigramas. Tirteo. Odas anacreónticas. Traducción nueva del griego por Leconte de Lisle, Gómez de la Mata G. (trad.), Valencia, Prometeo, «Serie Libros célebres españoles y extranjeros», s.d., 214 p. [Libro firmado y fechado: «J. Florencio Cortázar, mayo 1933».]

\section{Obra secundaria}

Wahl Jean, Estudio sobre el «Parménides» de Platón, M. Q. J. (trad.), Madrid, Espasa-Calpe, «Serie Nueva biblioteca filosófica», 1929, 261 p. [Libro firmado y fechado: «J. Florencio Cortázar, 1936».]

\section{Otros libros de la Biblioteca Cortázar}

Béguin Albert, L'âme romantique et le rêve: essai sur le romantisme allemand et la poésie française, Paris, Librairie José Corti, 1963, 416 p. [Libro firmado y fechado: «Cortázar París '66».]

Bréhier Émile, Historia de la filosofía. 1, La Antigüedad y la Edad Media. Náñez D. (trad.). Buenos Aires, Sudamericana, 1942, 703 p. [Libro firmado: «Julio Cortázar».]

Bury John Bagnell, A history of Greece to the death of Alexander the Great, New York, The Modern Library, c. 1913, 885 p. [Libro firmado y fechado: «Julio Denis XLI».]

Curtius Ernst Robert, Literatura europea y Edad Media. Frenk Alatorre M., Alatorre A. (trads.), México, FCE, 1955, 2 vols., 902 p.

Mallarmé Stéphane, Divagations, Paris, Eugène Fasquelle, 1922, 374 p. [Libro firmado y fechado: «J. Florencio Cortázar 26/8/35». Con dedicatoria de sus amigos que se lo regalaron en ocasión de su 21 cumpleaños.]

Marasso Arturo, Píndaro en la literatura castellana. Notas para un estudio, Buenos Aires, Coni, 1930, 39 p. [Con dedicatoria de Marasso: «A Florencio Cortázar, afectuosamente, Arturo Marasso».]

Thibaudet Albert, La poésie de Stéphane Mallarmé. Étude littéraire, Paris, Gallimard, 1920, 470 p. [Libro firmado y fechado: «Julio Denis 39». Con dedicatoria de su amigo Paco Reta: «Al afecto generoso del gran amigo Julio. Francisco Reta 39».]

Valéry Paul, Variété. 1. Paris, Gallimard, 1924, 252 p. [Libro firmado y fechado: «Julio Denis 38».]

\section{Libros consultados por Cortázar que no se encuentran en su biblioteca personal (1933-1936) ${ }^{127}$}

Diccionario Enciclopédico Hispanoamericano de Literatura, Ciencia y Artes, Barcelona, Montaner y Simón, 1887-1910, 29 vols.

Hésiode, Théogonie. Les travaux et les jours. Le Bouclier. Mazon P. (ed., trad.), Paris, Les Belles Lettres, 1928, $150 \mathrm{p}$.

Hesíodo, Teogonía, Segalá y Estalella L. (trad.), Barcelona, Tipografía «La Académica» de Serra Hnos. y Russell, 1910, 95 p. 
Homero, Ilíada, Segalá y Estalella L. (trad.), Barcelona, Montaner y Simón Editores, 1908, $443 \mathrm{p}$.

Marasso Arturo, Rubén Darío y su creación poética, Buenos Aires, Biblioteca Nueva, 1934, $408 \mathrm{p}$.

Nestle Wilhelm, Historia de la literatura griega, Echauri E. (trad.), Barcelona, Labor, 1930, $347 \mathrm{p}$.

Píndaro, Obras completas. Edición enriquecida con fragmentos de las obras de Anacreonte, Safo y Erina, Meabe T. (trad.), Paris, Garnier Frères, 1921, 347 p.

Saint-Victor Paul de, Las dos carátulas, Blanco-Belmonte M.R. (trad.), Buenos Aires, El Ombú, «Serie Biblioteca de los grandes maestros», 1933, 6 vols.

Steuding Hermann, Mitología griega y romana, Camón Aznar J. (trad.), Barcelona, Labor, 1927,224 p.

\section{NOTAS}

2. Julio Cortázar, carta a Graciela de Sola del 3 de junio de 1967, Cartas. 2. 1964-1968, Bernárdez A. (ed.), Buenos Aires, Alfaguara, 2000, p. 1155. Citaré las Cartas, a partir de ahora, por la sigla «C»y el número del volumen en cuestión, o sea, en este caso: C II: 1155.

3. Son abundantes las referencias a Heráclito, por sólo nombrar al filósofo más destacado, en la obra de Cortázar. Este aspecto de su obra lo he desarrollado en un artículo conjunto con Danny Praet, «Reversals of Fire. The philosophy of Heraclitus as thematic subtext of Julio Cortázar's “All Fires the Fire"», publicado en el Bulletin of Hispanic Studies, y en mi artículo «Más que un amateur esclarecido. La afición de Julio Cortázar por la filosofía de Heráclito», publicado en Neophilologus. En cuanto a las referencias a la literatura clásica en la obra de Cortázar, me refiero, por ejemplo, a la parodia de Petronio en el séptimo capítulo de Los premios (1960), la cita de Aulo Gelio en el capítulo 148, uno de los prescindibles, de Rayuela (1963), y los «plagios» de la Ilíada en Libro de Manuel (cfr. infra). El arte de Grecia, por su parte, está presente en los poemas «Los dióscuros» y «Grecia 59» (ambos de Salvo el crepúsculo, 1984), y en el cuento «El ídolo de las Cícladas» (Final del juego, 1964).

4. Desde muy joven, Cortázar tenía la costumbre de apuntar en la primera página del libro el año en que compró el libro, y de leerlo lapiz en mano, subrayando y comentando las frases que le interesaban; "peleándome con el autor, mandándolo al diablo o abrazándolo» (C I: 583). Con frecuencia Cortázar apuntaba también en la última página del libro los números de las páginas más destacadas. Ver Sara Castro-Klaren, «Julio Cortázar, lector. Conversación con Julio Cortázar», Cuadernos Hispanoamericanos, $\mathrm{n}^{\circ}$ 364-366, 1980, p. 12-13.

5. Hoy en día, uno de los pocos críticos que ha profundizado en las lecturas personales del escritor, tal como se encuentran en la Biblioteca Cortázar, es Daniel Mesa Gancedo, ver «De la casa (tomada) al café (Tortoni): historia de los dos que se entendieron: Borges y Cortázar» (2005). Más recientemente, en el octavo Coloquio Literario de la Feria Internacional del Libro de Monterrey (2008), también Gonzalo Celorio y Beatriz Barrantes-Martín se han dedicado a ciertas obras que Cortázar había leído.

6. Esto por varios motivos: siendo pobre, el joven Cortázar no tenía muchos libros, así que solía intercambiarlos con amigos o tomarlos prestados de su maestro Marasso (cfr. infra). Además, de los pocos libros adquiridos, sólo había podido llevarse algunos libros a París, es decir, los diez libros que le cabían en la maleta, lo que demuestra también el gran cariño que guardaba por los libros que ahora se pueden consultar. El resto de su biblioteca bonaerense, según Aurora 
Bernárdez, «quedó en un almacén y finalmente se perdió». Para la entrevista con Bernárdez, ver Francisco X. Fernández Naval, Respirar por el idioma: los gallegos y Julio Cortázar, Buenos Aires, Corregidor, 2007, p. 39.

7. Cortázar fue el mejor del grado: «Era el único 9 en lectura, ocupaba el segundo lugar con 8 en escritura, primero en idioma y primero compartido en aritmética con otro 9». Ver Jorge R. Deschamps, Julio Cortázar en Banfield. Infancia y adolescencia, Buenos Aires, Orientación gráfica, 2004, p. 68.

8. Osvaldo Soriano, «Reportaje a Julio Cortázar», 1983, p. 4. Cito por una versión impresa del texto digital.

9. Julio Cortázar, Último round, Barcelona, Destino, 2004, p. 239.

10. Soriano, op. cit., p. 4.

11. Así llamaron el sótano del café Edison de la avenida Rivadavia.

12. Luis Harss, «Julio Cortázar, o la cachetada metafísica», Los nuestros, Buenos Aires, Sudamericana, 1976, p. 263.

13. Soriano, op. cit., p. 4.

14. Soriano, op. cit., p. 4.

15. Prego, op. cit., p. 30.

16. Entre sus publicaciones se pueden mencionar Hesíodo en la poesía castellana (1926), Píndaro en la poesía castellana (1930), Cervantes y la invención del Quijote (1954) y Estudios de la literatura castellana (1955). Publicó varias obras poéticas (Bajo los astros (1911), La canción olvidada (1915) y Melampo (1931), para sólo citar algunas) y ganó el premio de poesía en 1924.

17. Soriano, op. cit., p. 4.

18. Su cariño frente a Marasso también se expresa más tarde en su vida. Aun en 1967 y 1970, respectivamente, Cortázar declara que participaría con mucho gusto en un homenaje a Marasso (C II: 1163) y que un día le gustaría escribir sobre él: «Su recuerdo, lo sé, tomará cuerpo en algún texto, pero el día no ha llegado» (C III: 1421).

19. Aunque Charles Marie René Leconte de Lisle (1818-1894) fue el traductor de varias de las obras clásicas de la Biblioteca Cortázar (cfr. infra), aquí se refiere más bien a la poesía parnasianista del propio Leconte de Lisle.

20. Julio Cortázar, Obras completas. 4, Poesía y poética, Yurkievich S. (ed.). Barcelona, Galaxia Gutenberg, Círculo de Lectores, 2005, p. 206. A partir de ahora citaré las Obras Completas por las siglas «OC» y el número del volumen en cuestión, o sea, en este caso: OC IV: 206.

21. John Luis Marambio, Julio Cortázar y la contra-novela, Michigan, Texas Tech University, 1980, p. 102. La predilección cortazariana por el mito del Minotauro se puede vincular con su atracción por los monstruos mitológicos y los laberintos. Ver Prego, op. cit., p. 136 y Harss, op. cit., p. 266.

22. Aparentemente, la frase misteriosa «Fueron a conquistar el vellocino de oro», que había leído en un libro de la biblioteca casera, apelaba a la imaginación del joven Cortázar. Ver Julio Cortázar, «Para llegar a Lezama Lima», La vuelta al día en ochenta mundos. 2. Madrid, Siglo XXI de España editores, 2007, p. 80.

23. Julio Cortázar, Carol Dunlop, Los autonautas de la cosmopista. Un viaje atemporal París-Marsella, Barcelona, Muchnik, 1983, p. 150.

24. Prego, op. cit., p. 159.

25. Ver Eduardo Montes-Bradley, Cortázar sin barba, Buenos Aires, Sudamericana, 2004, p. 114.

26. Ver también la siguiente declaración de Ofelia Cortázar en Mario Goloboff, Julio Cortázar. La biografía, Buenos Aires, Seix Barral, 1998, p. 16: «[...] como le daba por la mitología, el poema es todo en términos mitológicos, y termina hablando de las ondas de Memé.»

27. Soriano, op. cit., p. 4.

28. Ver el testimonio siguiente en Prego, op. cit., p. 43-44: «[...] ya a partir de los 16 o 17 años yo era un omnívoro capaz de devorar los Ensayos de Montaigne, alternados con las Aventuras de Buffalo Bill, [...] y los Diálogos de Platón.» 
29. Ver Lucille Kerr, «Interview. Julio Cortázar», Diacritics, $\mathrm{n}^{\circ}$ 4, 1974, p. 40: «[...] what would I have been if I had not read Homer in Spanish, Dostoievski in English, Catullus in Italian, Plato in French?» Es probable que se trate de una edición francesa de la biblioteca casera, ya que, al contrario de los demás autores citados, las obras completas de Platón no se encuentran en la Biblioteca Cortázar.

30. François Hébert, «An Interview with Julio Cortázar», en Jaime Alazraki (bajo la dirección de), Critical essays on Julio Cortázar, New York, G.K. Hall \& Co, 1999, p. 69. Esta impresión profunda se confirma cuando cuenta los Diálogos de Platón entre los libros que salvaría de la conflagración universal. Ver Evelyn Picon Garfield, Cortázar por Cortázar, Xalapa, Universidad Veracruzana, 1981, p. 41.

31. En mi opinión se trata de Marasso, pero en otra declaración Cortázar explica que leyó a Aristóteles con Fatone. Ver Soriano, op. cit., p. 4.

32. Prego, op. cit., p. 188.

33. Kerr, op. cit., p. 37.

34. Ernesto González Bermejo, Conversaciones con Cortázar, Barcelona, Edhasa, 1978, p. 64. El énfasis es mío.

35. A saber, en Albert Thibaudet, La poésie de Stéphane Mallarmé. Étude littéraire, Paris, Gallimard, 1920 , p. 424, apuntó «la teoría de los ciclos (Heráclito)» al margen de un pasaje sobre el eterno retorno.

36. Posteriormente, Cortázar recuerda la figura de Píndaro en Imagen de John Keats, cuando, en su análisis del poema «Lamia», asocia los triunfos de Lucio en las carreras de carros con las odas del poeta griego: «¿[Lamia] No vio a Píndaro? Quizás estaba allí, panegirista» (OC IV: 1126).

37. El nombre de Esquilo aparece también en los apuntes marginales que hizo Cortázar en otros libros, a saber, en John Bagnell Bury, A history of Greece to the death of Alexander the Great, New York, The Modern Library, c. 1913, p. 223, que leyó en 1942, y en Thibaudet, op. cit., p. 274. Más tarde, en una carta a Jean Barnabé de 1955, comparará la Orestíada de Barrault con la de Esquilo: «Barrault ofreció una versión de l'Orestie, con una primera parte extraordinaria, pero muchos defectos en el resto. No se puede presentar a los dioses griegos (y sobre todo los de Esquilo, salvajes y primitivos) como si fueran personajes de Marivaux» (C I: 328).

38. En la nota preliminar a su poema «Grecia 59» (Salvo el crepúsculo, 1984), escrita a inicios de los ochenta.

39. Soriano, op. cit., p. 4.

40. En un apunte que hizo en 1933 en los Himnos órficos, obra recopilada en su ejemplar de Teócrito (cfr. infra), se refiere a Las Bacantes de Eurípides: «Véase el capítulo Las Bacantes (comentario sobre el drama homónimo de Eurípides) que hace Paul de Saint-Victor en la parte correspondiente a Eurípides (pág. 152) de Las dos carátulas, y se notará la relación entre el culto de Baco y este idilio» (XXVI, 143). La cifra romana corresponde al número del idilio; la arábiga al número de la página del libro. La versión inglesa de las tragedias de Eurípides que se encuentra todavía en la Biblioteca Cortázar data sólo de 1960. Cortázar la compró en 1962.

41. Menciona a estos autores griegos en: Julio Cortázar, «La urna griega en la poesía de John Keats», Obra crítica. 2, Jaime Alazraki (ed.), Madrid, Alfaguara, 1994, p. 38: «[...] ese aire dionisíaco que circula inconfundible por Safo, Anacreonte, Baquílides, Píndaro, Corina, Teócrito y todo gran lírico griego». Como sabemos que leyó a Píndaro y Teócrito en su juventud, es muy probable que también las demás lecturas líricas daten de este período.

42. Soriano, op. cit., p. 4.

43. Cortázar sacó un 9,87 en esta materia en el quinto año de la Escuela Normal. Ver sus clasificaciones finales en Emilio Fernández Cicco, El secreto de Cortázar, Buenos Aires, Belgrano, 1999, p. 205. 
44. Según Fernández Cicco, op. cit., p. 36, Cortázar se llevó su ensayo inédito después a Bolívar: «Cortázar pensó que aquel lío de papeles quizás podía servirle en sus clases y lo agregó al equipaje camino a Bolívar».

45. ¿Quizá en esta ocasión Marasso le regaló el ejemplar firmado de Píndaro en la poesía castellana (1930) que todavía se encuentra en la biblioteca cortazariana? La dedicatoria reza así: «A Florencio Cortázar, afectuosamente, Arturo Marasso».

46. No lo recuerda el propio Cortázar sino Andrés Fava, un personaje autobiográfico de El examen (1950).

47. Los datos bibliográficos precisos de todos los libros clásicos de la Biblioteca Cortázar se encuentran en una sección por separado de la bibliografía.

48. Aunque Cortázar afirmó en Castro-Klaren, op.cit., p.22, que más tarde leyó el poema homérico en mejores traducciones, la traducción de Gómez de la Mata es hoy en día la única que se encuentra en la Biblioteca Cortázar.

49. Castro-Klaren, op. cit., p. 22.

50. Castro-Klaren, op. cit., p. 21.

51. Castro-Klaren, op. cit., p. 22.

52. Ibid.

53. Castro-Klaren, op. cit., p. 21. Es consabido que los conceptos del pasaje y del otro lado forman elementos claves en la poética de Cortázar.

54. Castro-Klaren, op. cit., p. 22.

55. Es interesante ver cómo cambia también los nombres propios extraños en «Uno de tantos días de Saignon» (Último round, 1969), aunque en este texto todavía cita la traducción de Gómez de la Mata.

56. Para distinguir este tipo de apuntes de las verdaderas fichas del fichero (ver 2.5), me sirvo de la palabra «ficha(s)» entre comillas.

57. En adelante la cifra romana siempre corresponde al canto o al capítulo de la obra citada; la arábiga a la página del libro.

58. En la Biblioteca Cortázar no se encuentra ninguna edición griega de la Ilíada. Aunque Cortázar solo seguía un año de griego, resulta que sabía por lo menos descifrar el texto original.

59. Cito el fragmento por la edición que tenía Cortázar: «La correa de cada preservador escudo se empapará con la transpiración de cada pecho, y la mano guerrera ha de cansarse oprimiendo la lanza, y el caballo humeará sudoroso de transportar el carro sólido. ¡Ah! Y sabed que aquél a quien yo vea lejos del combate y próximo a las naves espolonadas no podrá impedir que le devoren los perros y las aves de rapiña» (II, 39). Esta escena no vuelve en la producción posterior del escritor.

60. Este fragmento no reaparecerá en la obra de Cortázar.

61. En la nota preliminar a «Grecia 59» (Salvo el crepúsculo, 1984).

62. En «La urna griega en la poesía de John Keats» vuelve al escudo homérico, al comentar el motivo poético de la écfrasis que se presencia en la «Oda a una urna griega» de Keats. En el mismo ensayo Cortázar comenta la importancia que Homero debe haber concedido a dicha descripción: «debió parecerle capital pues la interpola quebrando la acción en su momento más dramático y no vacila en aislarse del escenario épico para demorar en las escenas que Hefesto martilla sobre el caliente bronce» (OC IV: 1023).

63. En una larguísima nota al pie del citado ensayo sobre Keats, Cortázar lo ilustra con ejemplos copiados de su edición de Homero, en los que enfatiza esta «interfusión», al poner en cursiva las palabras que se asocian con otra forma de arte: «... Las novias salían de sus habitaciones y eran acompañadas por la ciudad a la luz de antorchas encendidas, oíanse repetidos cantos de himeneo, jóvenes danzantes formaban ruedos, dentro de los cuales sonaban flautas y cítaras.» (Homero, «Escudo de Aquiles», Ilíada, Canto XVIII). «... Y arrastraba, asiéndole de los pies, por el campo de batalla a un tercero que ya había muerto; y el ropaje que cubría su espalda estaba teñido de sangre 
humana...» (Id.).

«... Doncellas y mancebos, pensando en cosas tiernas, llevaban el dulce fruto en cestos de mimbre; un muchacho tañía suavemente la armoniosa cítara y entonaba con tenue voz un hermoso lino y todos le acompañaban cantando, profiriendo voces de júbilo... (Id.)» (OC IV: 1025).

64. «[Tetis] Dijo así, y el Cronida asintió con un guiño de sus cejas, y entonces los cabellos inmortales del soberano Zeus ondearon desde su inmortal testa, y temblar hizo el espacioso Olimpo» (Il. I, v. 528-30). Cito por la versión de Antonio López Eire (2001), p. 71-72.

65. Cortázar no apuntó nada en la segunda parte, ni en los epigramas ni en la Batracomiomaquía.

66. En los demás apuntes Cortázar agrega al nombre erróneo «Polideo» el nombre correcto «Pólux» (XI, 173) y añade una explicación geográfica, digna de su fichero, al nombre «Panapeo»: «Panapeo, alrededores del Parnaso, en la Fócida» (XI, 181).

67. «Del Atreida Agamenón» (IV, 49).

68. Es éste el fragmento marcado del ejemplar que tenía Cortázar: «De todo les ofreció; ellos comieron y bebieron, y tocándoles con una varita, les encerró en pocilgas» (X, 153). El párrafo lo marcó a lápiz, al igual que los demás apuntes del '33.

69. Lo fascinante de este pasaje de la Odisea es que Cortázar volvió a leerlo en 1964 y que también marcó las huellas de su relectura, esta vez en tinta azul. Con motivo de la adaptación cinematográfica de su cuento «Circe» por Manuel Antín, la organización del Festival Internacional de Cine de Berlín le había pedido al director argentino de cine más datos sobre la trama del relato cortazariano. Cuando Antín le escribe a Cortázar pidiéndole dicha información suplementaria, él le contesta que ha vuelto a leer la Odisea por primera vez. Es interesante ver que en su respuesta Cortázar menciona el «pan envenenado» (C II: 714) de Circe, ya que fueron precisamente estas palabras las que había subrayado durante su relectura de la Odisea: «pero puso veneno en el pan» (X, 153). Los demás párrafos que indicó en esta lectura se relacionan también con el cuento. Se trata de la descripción de la voz y la tela de Circe $(\mathrm{X}, 153)$ y del antídoto de Hermes, el moly (X, 155).

70. Para este aspecto, ver también el análisis del cuento de Houvenaghel y Monballieu (2008).

71. En el Himno a Hermes, Cortázar cambia «Hefesto» en «Hermes (error)» (166).

72. No puedo reproducirlas aquí en su totalidad.

73. Puedo citar los ejemplos siguientes: «Taumante (Segalá) Padre de Iris» (16), «Ploto (Segalá)»

(16), «Zánganos (Segalá)» (30), «La Suerte (Segalá)» (30) y «Crujía (Segalá)» (34).

74. Lo prueba su apunte «Error seg. ed. "Belles Lettres"». [...] La que está [...] no aparece en la traducción francesa» (21).

75. Cfr. infra bajo 2.5 .

76. Nombre ilegible.

77. En Imagen de John Keats, citando toda la «Titanomaquia» de Hesíodo, Cortázar copia la misma observación sobre Leopardi: «[...] una lucha feroz que Hesíodo describe en su Teogonía con versos que Leopardi hallaba comparables a los más bellos de Homero.» (OC IV: 1160) El fragmento de Leopardi al que se refiere forma parte de la introducción que el italiano redactó para su traducción poética de la «Titanomaquia» (1817).

78. Se trata de una nota al pie que Cortázar agrega sobre Heracles: «Anfitrión Alceida, hijo de Alceo, Señor de Tirento [ilegible]. Heracles fue llamado también Alceo y Alcides» (55).

79. En «La urna griega en la poesía de John Keats». Al comentar la écfrasis del escudo de Heracles se pregunta si «es sólo por influencia [de Homero] que Hesíodo, obrando del mismo modo [que Homero], suspende la inminencia del encuentro entre Heracles y Cicno y nos conduce sinuosamente por los panoramas abigarrados que pueblan el escudo del héroe» (OC IV: 1023).

80. En una larga nota al pie de «La urna griega», la misma que ya he citado en el contexto de la Ilíada, Cortázar citará también varios fragmentos de su edición de Hesíodo, enfatizando otra vez ciertas palabras por medio de la cursiva: «... Su traje manchado de sangre humana flotaba en torno a sus hombros; miraba ella con ojos espantosos y prorrumpía en clamores...» (Hesíodo, Escudo 
de Heracles) «... Y rechinaban sus dientes en tanto que el Anfitrionada combatía...» (Id.). «... Estaba en pie, rechinando los dientes, y un remolino de polvo espeso envolvía sus hombros, y este polvo estaba húmedo de lágrimas...» (Id.). «... Volando en el aire, unos cisnes prorrumpían en altos clamores, y otros muchos nadaban en la superficie del agua, y cerca de allí jugaron los peces, cosa maravillosa hasta para Zeus retumbante...» (Id.), en OC IV: 1025.

81. Esta vez Cortázar transcribe la palabra griega.

82. Los otros apuntes de Los trabajos y los días constan de una nota sobre la etimología de Pandora -«Pandora: la obsequiada por todos» (74) - y una observación sobre un personaje mitológico: «No se debe confundir a Horco con Plutón, llamado así a veces» (103).

83. Al nombre de Perséfone añade, por ejemplo: «Hija de Demeter y reina del Hades» (I, 109). También explica quiénes son Pafia - «Uno de los muchos nombres de Afrodita (Citeres, Anadyomena, Cipris, etc.)» (I, 110) - y Jacinto: «Amado ardientemente por Febo Apolo, fue muerto en un descuido por él mismo, al golpearle con un disco» (VII, 115).

84. Al nombre de Europa añade, por ejemplo, que fue la madre «de Minos y Rabdomante» (II, 129) y debajo del nombre «Edoneo» pone el nombre más conocido de este dios: «Hades» (III, 130).

85. Sobre Proteo redacta, por ejemplo, la «ficha» siguiente: «Proteo es uno de los muchos nombres dados al dios del mar (Nereo, Forcio, Glauco, Tritón). Etimológicamente significa el primer nacido» (162). No puedo citar todos los apuntes encontrados que contienen el mismo tipo de información.

86. «La estuaria y el bajorrelieve presentan siempre los curetes armados; la leyenda dice que golpeando sus escudos cubrieron el llanto de Zeus niño, evitando que Cronos lo descubriera » (XXXVII, 172).

87. «La victoria - Recuérdese el templo de Nike áptera (victoria sin alas) en la Acrópolis de Atenas» (XXXII, 168).

88. «El asiento principal de Demeter estaba en Eleusis en Atenas (N.O.) que se hizo famosa por los misterios (fiestas eleusinas) que allí se celebraban. Su famoso templo de Demeter fue destruido por los Persas en 484 a. J. C» (XXXVIII, 174).

89. Más en particular, en «Perfume de Eos».

90. Palabra ilegible.

91. Más tarde, en su ensayo «La urna griega en la poesía de John Keats» y en Imagen de John Keats, Cortázar se referirá al Idilio I de Teócrito: «¿Y hay sólo reflejo lejano en el cariñoso pormenor con que Teócrito describe el vaso que ha de premiar al bucolista de su primer idilio?» (OC IV: 1023)

92. Cortázar corrige la traducción de Gómez de la Mata y la reemplaza por la de Marasso: «¡Mormo!, el caballo muerde (Marasso)» $(\mathrm{XV}, 84)$.

93. En su ejemplar de los Idilios de Teócrito, Cortázar había apuntado las siguientes referencias a la monografía de Nestle: -«Según W. Nestle, este poema es probablemente de Bión de Smirna; se le encuentra también en Anacreonte» (XIX, 105). - «Dice Nestle: “a las composiciones

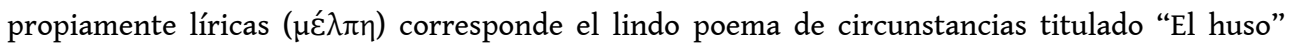
(28) concebido en el metro llamado de esclepiadeos mayores con el que el poeta acompañaba un regalo a la esposa de su amigo Nicias - Historia de la literatura griega"» (XXVIII, 154). - «Dice Nestle que este idilio no es de Teócrito, sino un canto bizantino» (XXX, 156).

94. «Pluto es el hijo de Demeter y el héroe Jasión [Yasión]; simboliza la riqueza, y se le representa bajo la forma de un anciano ciego; en general es dios insignificante y ridículo; véase la Teogonía de Hesíodo, pág. 45 y el comentario a Pluto (comedia de Aristófanes) de Saint Victor» (X, 63), apunta Cortázar. Más tarde, en 1936, comprará su ejemplar personal de las comedias de Aristófanes.

95. Los Dióscuros volverán a aparecer en 1953 en un poema cortazariano que lleva el mismo nombre (OC IV: 298-9; ver también C I: 277).

96. «Es la misma sensibilidad crecida en angustia, el obstinado adherir al presente para resistir la declinación, que torna casi terribles por contraste las odas anacreónticas» (OC IV: 1022). En una 
nota al pie de página agregará algunos ejemplos, citando por su traducción de segundo grado que describe como «la versión de Leconte de Lisle» (OC IV: 1022).

97. Goloboff, op. cit., p. 31.

98. Fernández Cicco, op. cit., p. 36.

99. Facundo de Almeida, su dueño actual, me contó cómo llegó en su poder. Transcribo un fragmento de un correo electrónico suyo que me envió el 1 de octubre de 2008: «En el año 2004, en ocasión de presentarse la exposición en Buenos Aires [Presencias/Cortázar] me hicieron una entrevista por la radio, y una oyente se comunicó a la emisora diciendo que quería contactarse conmigo. Fue así que llegó a mí una amiga de Ofelia -hermana de Cortázar- quien conservaba en su poder este fichero, dos libros de André Malraux que pertenecieron a la colección de Cortázar. [...] Este material se lo regaló Ofelia Cortázar a esta señora antes de morir, y ésta última al escuchar la entrevista pensó que estaría bien conservado en mis manos, y fue por ello que me lo regaló».

100. En el dorso de las fichas figuran partes de formularios oficiales, que quizá provienen de la Caja de Jubilaciones y Pensiones donde trabajó su madre, María Herminia Descotte de Cortázar.

101. Cito sólo un par de títulos de la vasta bibliografía de Fatone: Sacrificio y gracia. De los Upanishads al Mahayana (1931), El budismo nihilista (1941), Introducción al conocimiento de la filosofía en la India (1942) e Introducción al existencialismo (1953). En 1957 Fatone fue nombrado embajador en India. Ver Goloboff, op. cit., p. 104.

102. No obstante, en las clasificaciones finales de Cortázar, tales como las he consultado en Fernández Cicco, op.cit., p. 204-205, no aparecen las materias «Teoría del conocimiento»o «Filosofía».

103. Según la clasificación final del séptimo año del Mariano Acosta, Cortázar sacó un 8,12 . Ver Fernández Cicco, op. cit., p. 205.

104. Soriano, op. cit., p. 4.

105. Ningún volumen de la vasta obra de Aristóteles se encuentra en la Biblioteca Cortázar.

106. Soriano, op. cit., p. 4.

107. Esto coincide con la declaración siguiente de Aurora Bernárdez, mencionada en la tesis doctoral de Sylvie Protin, Traduire la lecture. Aux sources de Rayuela: Julio Cortázar, traducteur, Université Lumière Lyon II, 2003, p. 15. Cito por una versión impresa de su tesis digital: «Ceci recoupe une information recueillie auprès de Aurora Bernárdez: il semble que ce soit Vicente Fattone [sic], un ancien professeur de Cortázar au Mariano Acosta, qui l'ait mis en contact avec les éditions Sopena, afin de traduire pour la revue Leoplán. Ce petit groupe d'amis très proches [Cortázar, Eduardo Jonquières y Paco Reta] traduisait donc de concert pour la même revue».

108. Prego, op. cit., p. 188. Aunque a lo largo de su vida Cortázar tuvo menos contacto con su profesor de filosofía, en una carta de 1965 todavía recuerda que lo encontró durante su primer viaje a la India en 1956 y que allí hablaron mucho de los tiempos del Mariano Acosta (C II: 819).

109. Es este libro que le promete llevar a su amiga Merche en la carta de mayo de 1940: «Le llevaré el Parménides; [...]» (C I: 83).

110. Es imposible reproducir en estas líneas todos los apuntes cortazarianos en el libro de Wahl. Las anotaciones relacionadas con la filosofía de Heráclito las comento en el artículo enviado a la Revista Synthesis, «Más que un amateur esclarecido. La afición de Julio Cortázar por la filosofía de Heráclito».

111. Para dar una selección de ejemplos, Cortázar apuntó «Platón» al margen de la cita siguiente de Franz Cumont, tal como se encuentra en Ernst Robert Curtius, Literatura europea y Edad Media, M. Frenk Alatorre, A. Alatorre (trads.), México, FCE, 1955, p. 332: «Al mismo tiempo, las hijas de Mnemósine recuerdan a la razón las verdades que ésta conoció en una vida anterior; [...].» Escribió «Platón lo indagó» al lado del siguiente pasaje de Émile Bréhier, Historia de la filosofía. 1, La Antigüedad y la Edad Media, D. Náñez (trad.), Buenos Aires, Sudamericana, 1942, p. 49: «El cambio o movimiento se nos presenta, por lo pronto, como tránsito o paso de ser la cosa algo 
determinado a ser otro algo determinado: la cosa que es blanca pasa a ser negra. Lo blanco y lo negro son ser quieto pero el paso de lo uno a lo otro no es ser ya blanco ni ser aún negro; es un ser en marcha de la blancura a la negrura» (49).

112. En el Diario de Andrés Fava; OC II: 559.

113. En Imagen de John Keats (OC IV: 1037) y en «/que sepa abrir la puerta para ir a jugar», Julio Cortázar, Último round, op. cit., p. 234.

114. En Harss, op. cit., p. 288, Picon Garfield op. cit., p. 12, 41, 71, González Bermejo, op. cit., p. 16, 34-35 y Prego, op. cit., p. 60.

115. Se trata, por ejemplo, del apunte «Las Ideas» que escribió al margen de «Crise de vers» de Stéphane Mallarmé, Divagations, Paris, Eugène Fasquelle, 1922, p. 251. Otro ejemplo es el comentario «En suma, las ideas platónicas» que agregó al margen de Paul Valéry, «Au sujet d'Eureka», Variété. 1. Paris, Gallimard, 1924, p. 116. También se refiere a las Ideas de Platón, cuando habla de los cuentos fantásticos, en Prego, op. cit., p. 60, o cuando comenta el concepto que tiene Borges de Buenos Aires, en Picon Garfield, op. cit., p. 12.

116. En González Bermejo, op. cit., p. 16.

117. En 1938 Cortázar apuntó «Crátilo [Platón]» al margen del pasaje siguiente de Valéry, op. cit., p. 47, que parcialmente había subrayado: «Songez à la subtilité et à la volonté qu'il leur a fallu pour accomplir l'ajustement si délicat, si improbable, du langage commun au raisonnement précis; songez aux analyses qu'ils ont faites d'opérations motrices et visuelles très composées; et comme ils ont bien réussi dans la correspondance nette de ces opérations avec les propriétés linguistiques et grammaticales».

118. Al hablar del tema de los dobles Cortázar explica la historia platónica del andrógino en González Bermejo, op. cit., p. 34-35. El mismo tema ya lo había tocado antes, es decir, en 1966, durante la lectura de L'âme romantique et le rêve: essai sur le romantisme allemand et la poésie française de Albert Béguin, Paris, Librairie José Corti, 1963. Suena indignada la pregunta «Et Platon, alors?» que Cortázar apuntó al margen de la siguiente declaración de Béguin, p. 73: «Baader fut le premier d'entre eux à revenir à ce mythe [le mythe de l'androgyne] que l'on trouve, sous diverses formes, chez Philon le Juif, chez Scot Erigène et chez Boehme».

119. Durante la lectura de Thibaudet, op. cit., obra leída en 1939, Cortázar apuntó los nombres de estos diálogos al margen de la siguiente frase, p. 139: «Toujours monte à l'esprit de Mallarmé le problème qui hanta la maturité de Platon: N’y a-t-il pas un être du non-être?» Se trata de los títulos de dos diálogos platónicos tardíos que el propio Thibaudet había mencionado antes en $\mathrm{p}$. 107-108.

120. En González Bermejo, op. cit., p. 16.

121. Cortázar apuntó «Parm.» al margen de la siguiente frase de Émile Bréhier, op. cit., p. 49: «Ser es para ellos [los griegos] identidad de una cosa consigo misma: ser lo que es desde siempre y para siempre, absoluto reposo ontológico» (49). No se sabe cuándo Cortázar leyó el estudio de Bréhier.

122. En Diario de Andrés Fava (1950), cfr. infra.

123. En González Bermejo, op. cit., p. 16.

124. En Diario de Andrés Fava (1950): «Es evidente que primero somos oneness y recién después - oh inteligencia, perra magnífica - viene la parcelación. Del todo a las partes, como le gustaba al viejo Parménides, cúya es la Gestalt» (OC II: 527).

125. En el apunte que figura en la primera página del segundo tomo explica por qué no compró el primer tomo de las Comedias: «Tomo I lo tiene Castro». No sé exactamente quién es, pero parece ser un amigo de Cortázar de la época del Mariano Acosta con quien solía intercambiar libros.

126. Se trata de un apunte en John Bagnell Bury, A history of Greece to the death of Alexander the Great, New York, The Modern Library, c. 1913, p. 168. La frase «These were called Knights» de Bury debe haberle recordado Los caballeros de Aristófanes. Cortázar compró el libro de Bury en 1941. 
127. No se sabe qué edición había consultado. En la lista bibliográfica me refiero a las ediciones que he encontrado en el catálogo digital de la Biblioteca Nacional de Maestros de Buenos Aires, un lugar de estudio quizá frecuentado por el propio Cortázar.

\section{RESÚMENES}

El presente artículo intenta demostrar que el joven Julio Cortázar (1914-1984) había gozado de una formación clásica sólida en Buenos Aires (1929-1936). La autora de este ensayo es la primera en explorar los libros anotados de su biblioteca personal como testimonios sobre su vocación helenística.

Cet article montre que le jeune Julio Cortázar (1914-1984) avait reçu une solide éducation classique à Buenos Aires (1929-1936). L'auteur de l'étude est la première à explorer les livres annotés de sa bibliothèque personnelle comme témoignages de sa vocation d'helléniste.

This article shows that the young Julio Cortázar (1914-1984) enjoyed a profound classical education in Buenos Aires (1929-1936). The author of this essay is the first one to explore as testimonies of his calling as Hellenist, the annotated books in his personal library.

\section{ÍNDICE}

Mots-clés: Julio Cortázar, tradition classique, bibliothèque

Palabras claves: Julio Cortázar, tradición clásica, biblioteca

\section{AUTOR}

\section{AAGJE MONBALLIEU}

Université de Gand - Belgique 